\title{
ASSESSMENT OF PERSONAL EXPOSURE FROM RADIOFREQUENCY- ELECTROMAGNETIC FIELDS IN AUSTRALIA AND BELGIUM USING ON-BODY CALIBRATED EXPOSIMETERS
}

\author{
${ }^{1}$ Chhavi Raj Bhatt, ${ }^{2}$ Arno Thielens, ${ }^{1}$ Baki Billah, ${ }^{1}$ Mary Redmayne, ${ }^{1}$ Michael J. Abramson, ${ }^{1}$ Malcolm R. Sim, \\ ${ }^{3,4,5}$ Roel Vermeulen ${ }^{2}$ Luc Martens, ${ }^{2}$ Wout Joseph, ${ }^{1}$ Geza Benke \\ ${ }^{1}$ Centre for Population Health Research on Electromagnetic Energy (PRESEE) \\ School of Public Health and Preventive Medicine, Monash University \\ The Alfred Centre, 99 Commercial Road, Victoria 3004, Melbourne, Australia \\ ${ }^{2}$ Department of Information Technology, Ghent University/iMinds, Technologiepark - Zwijnaarde 15, Ghent B- \\ 9052, Belgium \\ ${ }^{3}$ Institute for Risk Assessment Sciences (IRAS), Division Environmental Epidemiology, Utrecht University, \\ Yalelaan 2, 3584 CM Utrecht, The Netherlands \\ ${ }^{4}$ Julius Centre for Health Sciences and Primary Care, University Medical Center, Utrecht, The Netherlands \\ ${ }^{5}$ Imperial College, Department of Epidemiology and Public Health, London, United Kingdom
}

\section{Introduction}

Concern regarding potential health and biological effects in humans from made sources of radiofrequency-electromagnetic fields (RF-EMFs) exposure has increased in the last decade. The International Agency for Research on Cancer has listed RF-EMF as a possible human carcinogen (Group 2B) (Baan et al., 2011). Furthermore, the World Health Organization emphasized the need of evaluation of personal exposures, from multiple RF-EMF sources for human epidemiological studies using objective measurements (van Deventer et al., 2011).

Personal RF-EMF exposures from far-field RF-EMF sources, such as those from mobile phone base stations, TV/radio signals, Wireless-Fidelity (Wi-Fi), have been evaluated employing exposimeters (Dürrenberger et al., 2014; Joseph et al., 2010; Röösli et al., 2010; Sagar et al., 2016; Urbinello et al., 2014a). These studies used a single exposimeter worn by human subjects to measure whole body RF-EMF exposure, but the exposimeters were not calibrated on body. In fact the use of a single exposimeter, may result in measurement uncertainties, particularly those related to the body shielding effects, residual calibration, and the frequency response of the measurement device (Bolte et al., 2011; Gajšek et al., 2015; Iskra et al., 2011; Mann, 2010; Neubauer et al., 2010). Iskra et al. (2011) suggested that the use of two exposimeters placed on different locations on the body may minimize the measurement uncertainties. It has also been demonstrated that wearing two on-body calibrated exposimeters, one on each hip, provided more accurate personal exposure measurements with a lower measurement uncertainty (Thielens et al., 2015a).

Studies investigating personal exposure levels from various far-field RF-EMF sources have been mainly conducted in European countries (Bolte \& Eikelboom, 2012; Frei et al., 2009; Gajšek et al., 2015; Joseph et al., 2010; Sagar et al., 2016; Urbinello et al., 2014b; 2014c; Vermeeren et al., 2013). There is a paucity of similar comparable data from elsewhere, including Australia. Therefore, a comparative study employing similar study protocols, involving countries outside Europe would be informative to the rest of the world. Only limited information has been reported on environmental exposure levels from mobile phone base stations and other RF-EMF sources in Australia (Henderson et al., 2014; Henderson \& Bangay, 2006; Rowley \& Joyner, 2012). Furthermore, we have recently published personal exposure data from $900 \mathrm{MHz}$ mobile phone base station downlink in Australia and Belgium (Bhatt et al., 2016a).

The aims of this study were: i) to demonstrate the assessment of personal exposure from various RF-EMF sources across different microenvironments in Australia and Belgium, with two on- 
body calibrated exposimeters, in contrast to earlier studies which employed single, non-onbody exposimeters ii) to systematically evaluate the performance of the exposimeters using (on-body) calibration and cross-talk measurements, and iii) to compare the exposure levels measured for selected microenvironments in the two countries.

\section{Materials and methods}

\subsection{Study areas}

The study was carried out in urban, suburban, and rural sites in Australia and Belgium. The microenviromental personal measurements were performed on a single person (CRB) during $7^{\text {th }}$ April- $8^{\text {th }}$ May and $27^{\text {th }}$ March $-6^{\text {th }}$ April 2015, respectively. The study areas in Australia mainly covered the urban and suburban regions of Greater Melbourne, and a rural site (Cathedral Range State Park). Similarly, urban and suburban regions of Ghent and rural regions of Mol in the Flemish region of Belgium were included in the study. A region was considered to be urban when the population density was $>400$ people per square kilometre (Joseph et al., 2010).

A total of 38 microenvironments (Table 1, appendix A), 19 each in Australia and in Belgium, were selected to evaluate personal exposures. Of them, the 34 matched microenvironments (17 each in each country) were: residential outdoor (urban), residential indoor (urban), office indoor (urban), park (urban), city center, library (urban), shopping center (urban), train station (urban), tram station (urban), bicycle (urban), bus (urban), car (rural/suburban), tram (urban), train, residential outdoor (rural/suburban), residential indoor (rural/suburban), and airport. In addition, subway station/ride (urban), mountain/forest (rural) in Australia, and bicycle (rural/suburban) and car (urban/suburban) in Belgium were also measured. These microenvironments have been described more fully in our previous paper (Bhatt et al., 2016a), and were similar to those of other studies (Bolte \& Eikelboom, 2012; Frei et al., 2009; Joseph et al., 2010; Röösli et al., 2010; Urbinello et al., 2014a, 2014b). We also evaluated the indoor exposures in airports of both countries, Tullamarine International Airport, Melbourne, and Brussels International Airport, Brussels.

The microenvironments were primarily of two types: stationary or mobile. The stationary microenvironments remained fixed while the subject moved around in the microenvironment, whereas the mobile microenvironments moved around during the data collection, whilst the subject essentially remained stationary. The mobile microenvironments included bus, train, tram, car and bicycle, whereas stationary microenvironments included the rest, except for subway station and ride, which was a mixed microenvironment (Bhatt et al., 2016a).

\subsection{Calibration procedure}

The procedure involved an on-body calibration of the ExpoM-RF 64 for 15 frequency bands (in contrast to previous studies where no on-body calibration was included). The frequency bands calibrated were Digital Video Broadcasting-Terrestrial (DVB-T), Long-Term Evolution (LTE) $800 \mathrm{MHz}$ downlink (DL) and uplink (UL), $900 \mathrm{MHz}$ UL and DL, $1800 \mathrm{MHz} \mathrm{UL}$ and DL, Digital Enhanced Cordless Telecommunications (DECT), Universal Mobile Telecommunications System (UMTS) $2100 \mathrm{MHz}$ UL and DL, Industrial, Scientific and Medical (ISM) $2.4 \mathrm{GHz}$, LTE $2600 \mathrm{MHz}$ UL and DL, Worldwide Interoperability for Microwave Access (WiMax) $3.5 \mathrm{GHz}$ and ISM $5.8 \mathrm{GHz}$. The central frequency levels calibrated were: $630 \mathrm{MHz}$ (DVB-T), $806 \mathrm{MHz}$ (LTE DL), $847 \mathrm{MHz}$ (LTE UL), $897.5 \mathrm{MHz}$ (900 UL), 942.5 MHz (900 DL), 1747.5 MHz (1800 UL), 1842.5 MHz (1800 DL), $1890 \mathrm{MHz}$ (DECT), $1950 \mathrm{MHz}$ (UMTS UL), $2140 \mathrm{MHz}$ (UMTS DL), $2442.5 \mathrm{MHz}$ (ISM 2.4 GHz), 2535 MHz (LTE $2600 \mathrm{UL}$ ), $2655 \mathrm{MHz}$ (LTE $2600 \mathrm{DL}$ ), $3500 \mathrm{MHz}$ (WiMax $3.5 \mathrm{GHz}$ ) and 5512.5 
MHz (ISM 5.8 GHz). Table 3 lists the different studied frequency bands and their frequency ranges. Note that although some bands have a technology-specific name (e.g. GSM 900 or $1800 \mathrm{MHz}$ ), other telecommunication technologies might be used in the same frequency band, for instance, LTE in the GSM $900 \mathrm{MHz}$ band. Therefore, the personal exposure measured in this study should be interpreted as being frequency-band-specific and not attributed to a certain communication technology. The ExpoM-RF 40 was calibrated only for $900 \mathrm{DL} \mathrm{MHz}$ band. The FM radio band was not calibrated since the anechoic chamber used for the calibrations did not provide sufficient damping in this frequency band. We assumed that ExpoM-RF 40 would yield the same calibration responses as those of ExpoM-RF 64.

The ExpoM-RFs measure the incident frequency-band-specific electric field strengths $\left(E_{\text {inc }}\right)$. The exposimeter(s), when worn on the body during measurements, register the electric field strengths on the body ( $\left.E_{b o d y}\right)$ (Bolte et al., 2011, Thielens et al., 2015a). Therefore, on-body calibration measurements are required in order to assess the relationship between $E_{\text {inc }}$ and $E_{b o d y}$. The subject (a 35-year-old male; height $163 \mathrm{~cm}$ and weight $60 \mathrm{~kg}$ ) participated in the on-body calibration in order to perform the subsequent field measurements (Fig. 1a). The on-body calibration procedure is discussed in detail elsewhere (Bhatt et al., 2016a). The calibration procedure was executed in a fully anechoic chamber following the procedure described in Thielens et al. (2015a) and Bhatt et al (2016a) (see also appendix B).

\subsection{Exposure assessment}

Exposimeters were simultaneously employed in data collection across the microenvironments. Using traveler's money belts, the ExpoM-RF 64 and the ExpoM-RF 40 were attached to the left and right sides of the subject's hips (Fig. 1b). Both ExpoM-RFs were switched on and switched off simultaneously to synchronize the start and the end of the measurements. The root mean square (RMS) electric field strengths measured by the ExpoM RFs have been denoted as $\left(E_{r m s}\right)$, in $\mathrm{V} / \mathrm{m}$. The lower limits of detection (LOD) for each band of the ExpoM RFs are: 20 $\mathrm{mV} / \mathrm{m}$ (FM radio), $50 \mathrm{mV} / \mathrm{m}$ (ISM $5.8 \mathrm{GHz}$ ), $3 \mathrm{mV} / \mathrm{m}$ (LTE and WiMax), and $5 \mathrm{mV} / \mathrm{m}$ (for the remaining frequencies). The upper LOD is $6 \mathrm{~V} / \mathrm{m}$ in all frequency bands. The detection range of the ExpoM-RFs, with on-body calibration, is the value listed above, divided by the corresponding on-body response in the respective frequency bands. A light jacket worn by the subject covered both exposimeters while performing the measurements (Fig. 1b). The subject did not have any metal objects attached to his body during data collection.

All measurements were performed during the daytime $(9: 45 \mathrm{am}-6: 00 \mathrm{pm})$ or evening $(6: 00$ pm-11:00 pm) on weekdays, except those of residential indoor and residential outdoor (rural/suburban) in Belgium, which were performed during the weekends (2:30-2:45 pm and 11:00-11:15 pm respectively). Each measurement duration was 15 minutes per microenvironment. A similar measurement duration were employed in the personal exposure monitoring by Urbinello et al. (2014a, 2014b). A smartphone watch, in flight mode, was used to monitor measurement time. The measurement intervals for the ExpoM-RFs were chosen to be $3 \mathrm{~s}$ (Bhatt et al., 2016a). Two ExpoM-RFs collected a total of 600 samples (300 each) per measurement for each microenvironment. Information on activities undertaken during data collection and descriptions of the microenvironments were recorded in a diary.

Twenty three microenvironmental measurements (13 in Australia and 10 in Belgium) were performed twice to evaluate exposure variability during the first and second measurements. We attempted to obtain as much spatio-temporal matching as possible for the repeated microenvironments. Spatial matching of the stationary microenvironmental measurements was ensured by walking across the same area/route and towards the same direction. However, in 
the case of city center (Belgium), the measurements were performed across the same urban area, but involved walking along a different route. For the mobile microenvironments, the spatial matching was accomplished by sitting/standing at the same spot/around the same positions with respect to window and carriage dimension. All mobile microenvironment measurements, except for car (urban) and bus (urban) in Belgium, were performed on exactly the same routes. The temporal matching, for most of the measurements, was ensured by performing the measurements $\left(1^{\text {st }}\right.$ and $2^{\text {nd }}$ ) at similar times of the day, such as morning, evening or night.

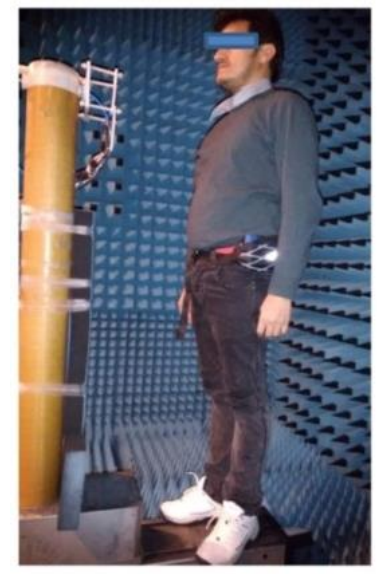

a

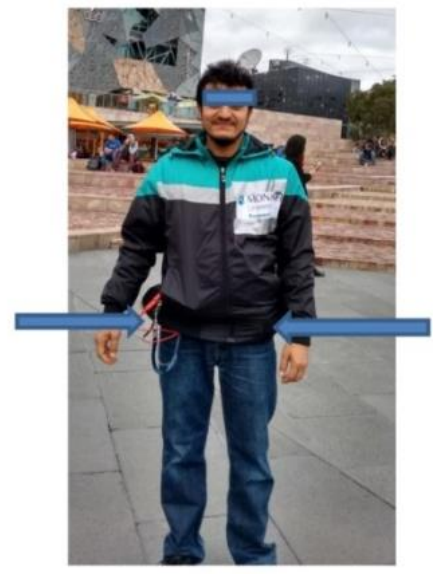

b

Fig. 1: The subject performing an on-body calibration of the ExpoM-RFs 64 in Ghent (a), and exposure measurement at a site in Melbourne using the on-body calibrated exposimeters (b) [arrows showing the locations of the ExpoM-RFs]

\subsection{Data processing and statistical analysis}

The analysis commenced with an assessment of the censored exposure data $\left(E_{r m s}\right)$ falling below the lower detection limit (LODs) in the respective frequency bands for each microenvironment. A Shapiro-Wilk test was performed on the untransformed and log-transformed data to evaluate normality. Furthermore, visual inspection of histograms and the normal Q-Q plots was also carried out.

We used the substitution approach in order to estimate summary statistics from the measured data. This is an accepted method in the science of environmental exposure assessment (Hewett \& Ganser, 2010). All left censored data (i.e. the data below LODs) were replaced with their frequency-specific respective values of LOD $/ \sqrt{ } 2$ (Ganser \& Hewett, 2010, Hewett \& Ganser, 2007). In ISM 5.8 GHz band (of the ExpoM-RF 64 data), numerous values < LOD (non-zero) and zero values were recorded. We replaced only the non-zero values $<$ LOD with $\mathrm{LOD} / \sqrt{2}$. The ExpoM-RF 64 measurements $<20 \mathrm{mV} / \mathrm{m}$ in the ISM $5.8 \mathrm{GHz}$ band were automatically set to zero as those values were most likely the result of crosstalk. For the ISM $5.8 \mathrm{GHz}$ data of the ExpoM-RF 40, we set all values $<20 \mathrm{mV} / \mathrm{m}$ as zero and all the non-zero values < LOD with $\mathrm{LOD} / \sqrt{2}$. The values below LODs of LTE $2600 \mathrm{MHz}$ DL and UL, and WiMax $3.5 \mathrm{GHz}$ bands were replaced with zeros for the measurements of the microenvironments that were situated in the areas not covered by these networks (Radio Frequency National Site Archive, 2016). All LTE $2600 \mathrm{MHz}$ (DL and UL) data of the microenvironments in Belgium, and those of residential outdoor and residential indoor (rural/suburban) in Australia were set to zero. In addition, the data of ISM $5.8 \mathrm{GHz}$ for the latter microenvironments in Australia, and those of WiMax 3.5 for the microenvironments located in rural/suburban regions of Belgium were also set to zero. Similarly, the WiMax 3.5 GHz and ISM 5.8 data of car (rural/suburban) in Australia 
was set to zero. In the case of mountain/forest (rural) in Australia, the data below the LODs of $900 \mathrm{MHz}$ DL, $900 \mathrm{MHz}$ UL, DVB-T, and FM Radio were substituted by their respective $\mathrm{LOD} / \sqrt{ } 2$, whereas all data for the remaining bands were set to zero.

Geometric means of the electric field signals $\left(E_{r m s}\right)$ measured with two ExpoM-RFs were calculated within the selected sample intervals using the formula; Geometric mean = $\left(E_{\text {ExpoM-RF40 }} \times E_{\text {ExpoM-RF64 }}\right)^{1 / 2} / R_{g m}$ (Bhatt et al., 2016a), where $R_{g m}$ is the geometric mean response of two ExpoM-RFs (see Appendix 2).. As Table 2 in Appendix 2 demonstrates, this geometric averaging leads to a lower prediction interval on the measured $E_{\text {rms }}$ values.

Neubauer et al. (2008) suggested that frequency-specific calibration factor(s) should be applied while estimating RF-EMF exposures because RF-EMF exposures close to the human body are otherwise underestimated, which depends on the dimension of the human body, positions of the body-worn exposimeter(s) and frequency types. We have not reported the individual exposures measured by the ExpoM-RFs for summary statistics. However, the frequencyspecific estimated median exposures provided by the individual ExpoM-RFs across all microenvironments of each country were used to evaluate the correlation between ExpoM-RF 40 and ExpoM-RF 64. The median exposure values obtained for 19 microenvironments with ExpoM-RF $64(n=19)$ and ExpoM-RF $40(n=19)$ per frequency band in both countries were used to perform the country-specific Spearman's rank correlation analysis. Furthermore, we also used median exposure levels measured with the ExpoM-RF 64 (without taking on-body calibration factors into account) across the 19 microenvironments in each country to compare the levels to those obtained with the concurrent use of the ExpoM-RF 64 and the ExpoM-RF 40. This would allow us to have a comparison between the exposure levels obtained with the use of a single non-on-body calibrated exposimeter (such as most of the personal exposimetry studies) and those obtained with the use of two on-body calibrated exposimeters (current study).

Summary statistics (mean, median, $25^{\text {th }}, 75^{\text {th }}$ and $95^{\text {th }}$ percentiles) of personal exposure across the measured bands were then calculated for all microenvironments in Australia and Belgium. The total and frequency-specific median exposures across all measured microenvironments in the both countries were obtained from the median values of the total and frequency-specific RF-EMF exposures, respectively. Furthermore, the statistics of personal exposure for each microenvironment were also calculated in terms of the four exposure categories: i) total exposure, which was equal to the square root sum of the 16 bands $\left(E_{\text {rms-FM }}^{2}+E_{\text {rms-DvB-T }}^{2}+\right.$ $E_{\text {rms-LTE800 UL }}^{2}+E_{\text {rms-LTE800 DL }}^{2}+E_{\text {rms-900 UL }}^{2}+E_{\text {rms-900 DL }}^{2}+E_{\text {rms-1800 UL }}^{2}+E_{\text {rms-1800 DL }}^{2}+$ $E_{\text {rms-DECT }}^{2}+E_{\text {rms-UMTS UL }}^{2}+E_{\text {rms-UMTS DL }}^{2}+E_{\text {rms-ISM } 2.4}^{2}+E_{\text {rms-LTE 2600 UL }}^{2}+E_{\text {rms-LTE 2600 DL }}^{2}$ $+E^{2}{ }_{\text {rms-WiMAX } 3.5}+E_{\text {rms-ISM 5.8) }}^{2}$;ii) mobile phone base station DLs exposure, the square root sum of all DL bands $\left(E_{\text {rms-LTE800 DL }}^{2}+E_{\text {rms-900 DL }}^{2}+E_{\text {rms-1800 DL }}^{2}+E_{\text {rms-UMTS DL }}^{2}+\right.$ $E^{2}$ rms-LTE $\left.2600 \mathrm{DL}\right)$; iii) mobile phone base station UL exposure, the square root sum of all UL bands $\left(E_{\text {rms-LTE800 UL }}^{2}+E_{\text {rms-900 UL }}^{2}+E_{\text {rms-1800 UL }}^{2}+E_{\text {rms-UMTS UL }}^{2}+E_{\text {rms-LTE } 2600 \mathrm{UL}}^{2}\right)$, and iv) broadcast exposure, the square root sum of FM radio and DVB-T bands $\left(E^{2}\right.$ rms-FM +

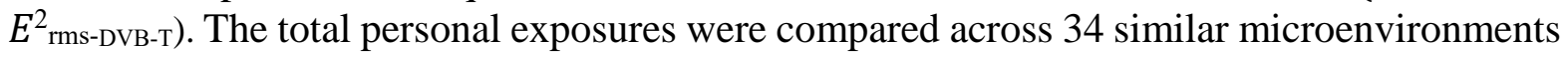
(17 in each country). Four microenvironments excluded from the comparison were: subway station/ride (urban), mountain/forest (rural) in Australia, and bicycle (rural/suburban), and car (rural/suburban) in Belgium. These were excluded because comparable corresponding microenvironments in the other country were not measured.

Wilcoxon rank sum tests were performed to: i) examine whether the exposures across the matched microenvironments in Australia and Belgium were different, ii) assess the exposure variability during the repeated measurements of a total of 20 microenvironments - Australia $(n=13)$ and Belgium $(n=7)$, iii) to evaluate if total, total DL, total UL and total broadcast median 
exposures across urban and rural/suburban microenvironments, as well as mobile and stationary microenvironments were different, and iv) to examine the difference between indoor and outdoor ISM 2.4 exposures. Furthermore, Spearman's rank correlation analysis was performed to examine the correlations between the median exposures of the compared microenvironments $(n=17)$ in the two countries.

For all statistical tests, $\mathrm{p}<0.05$ (two sided) was considered as statistically significant. Data analysis was carried out with STATA ver13.1 (StataCorp, College Station, TX, USA).

\section{Results}

\subsection{Calibration of the exposimeters}

Table 2 shows the results of the on-body calibration of the ExpoM-RF 64 attached to the left lateral hip of the subject as indicated in Fig. 1. The response and 50\% prediction interval for each band are denoted by $R$ and $P I_{50}$, respectively. The calculated geometric mean responses are denoted by $R_{g m}$.

Table 3 (appendix B) shows the measured cross-talk of ExpoM-RF 64 on the body of the calibrated subject. The cross-talk was determined using only the central frequencies of the bands. The cross-talk matrix was diagonal dominant and had a very small amount of off-body elements which were relatively high. The cross-talk of DECT induced in the $1800 \mathrm{DL}$ band was relatively large (approximately half the value of the response) and the cross-talk of WiMAX 3.5 induced in the ISM 5.8 was relatively large as well, although less important since WiMAX was less common (see Table 2). The ISM 5.8 band generally suffered the most from cross-talk. Similarly, DVB-T induced most cross-talk in other frequency bands, since it was the lowest frequency band. Table 4 (appendix B) lists the cross-talk matrix measured in the free space. The matrix was diagonal-dominant upper, central and lower frequencies.

\subsection{Data characteristics}

The measured exposure data of both exposimeters demonstrated varying degrees of censoring (Table 1, appendix A), depending upon the type of frequency band and microenvironment. The amount of censoring also varied between ExpoM-RF 40 and ExpoM-RF 64 measured data at the same microenvironment. Of all frequency-specific microenviromental measurements, $47 \%$ of the data in Australia and 50\% of the data in Belgium had 50\% or more censored data, when measured with both ExpoM-RFs. The proportion of censoring across the measured frequency bands was much higher for the measurements performed at suburban and rural microenvironments compared to those at urban microenvironments. In general, the three frequency bands demonstrating the least proportion of censoring in both countries were: 900 MHz DL, UMTS $2100 \mathrm{MHz}$ DL and ISM $2.4 \mathrm{GHz}$. The bands of LTE $800 \mathrm{UL}, 1800 \mathrm{UL}$, UMTS $2100 \mathrm{MHz}$ UL, WiMAX 3.5 and ISM 5.8 in both countries, plus LTE $2600 \mathrm{UL}$ and LTE 2600 DL in Australia, were amongst those demonstrating highest proportions of censoring.

Of all frequency band-specific microenvironmental measurements falling above the LODs, only $11 \%$ of the data in Australia and $18 \%$ of the data in Belgium followed lognormal distributions. Table 5 shows the correlation of frequency-specific estimated median exposure levels measured with ExpoM-RF 40 and ExpoM-RF 64, from all microenvironments in both countries. Overall, the measurements of two exposimeters showed high to very high positive 
correlations, Spearman rank correlation coefficients $\left(\mathrm{r}_{\mathrm{s}}\right)$ : 0.84-1 (Australia) and 0.72-0.99 (Belgium).

\subsection{Descriptive statistics}

Personal RF-EMF exposure across the measured frequency bands of all microenvironments in Australia and Belgium are summarized in Table 6 in terms of mean, median, $25^{\text {th }}, 75^{\text {th }}$, and $95^{\text {th }}$ percentiles. The five exposure sources providing the highest median exposures in Australia were: $1800 \mathrm{MHz}$ DL, $900 \mathrm{MHz}$ DL and $900 \mathrm{MHz}$ UL (0.07 V/m); UMTS $2100 \mathrm{MHz}$ DL (0.04 $\mathrm{V} / \mathrm{m})$; DECT and DVB-T (0.02 V/m). Similarly, $900 \mathrm{MHz}$ DL $(0.11 \mathrm{~V} / \mathrm{m})$, UMTS $2100 \mathrm{MHz}$ DL $(0.07 \mathrm{~V} / \mathrm{m}), 1800 \mathrm{MHz}$ DL $(0.06 \mathrm{~V} / \mathrm{m}), \mathrm{DVB}-\mathrm{T}$ and FM radio $(0.05 \mathrm{~V} / \mathrm{m})$ provided the five highest median exposures in Belgium.

Table 6 also compares the exposure levels measured with a single non-on-body calibrated exposimeter (ExpoM-RF 64) vs those with two concurrently employed on-body calibrated exposimeters (ExpoM-RF 64 and ExpoM-RF 40). The exposures measured with the two exposimeters were nearly 2-3 times higher than those measured with the single exposimeter. However, this was not the case for FM, ISM $2.4 \mathrm{GHz}$, LTE $2600 \mathrm{UL}$ and DL, where the exposure levels were of similar values.

Table 7 summarizes the descriptive statistics (mean, median, $25^{\text {th }}, 75^{\text {th }}$, and $95^{\text {th }}$ percentiles) of the personal RF-EMF exposure levels for total, total downlink, total uplink and total broadcast across different microenvironments in Australia and Belgium.

In Australia, the five highest total median exposure levels measured were: city center (4.33 $\mathrm{V} / \mathrm{m})$, residential outdoor (urban) $(0.75 \mathrm{~V} / \mathrm{m})$, park $(0.75 \mathrm{~V} / \mathrm{m})$, bicycle (urban) $(0.71 \mathrm{~V} / \mathrm{m})$, and train station $(0.48 \mathrm{~V} / \mathrm{m})$. Likewise, the five lowest total median exposure levels measured were: mountain forest (rural) $(0.02 \mathrm{~V} / \mathrm{m})$, shopping center (urban) $(0.04 \mathrm{~V} / \mathrm{m})$, residential indoor (rural/suburban) $(0.05 \mathrm{~V} / \mathrm{m})$, car (urban/suburban) $(0.05 \mathrm{~V} / \mathrm{m})$, and office indoor (urban) $(0.06 \mathrm{~V} / \mathrm{m})$.

In Belgium, the five highest total median exposures measured were: tram station $(1.95 \mathrm{~V} / \mathrm{m})$, city center $(0.95 \mathrm{~V} / \mathrm{m})$, park $(0.90 \mathrm{~V} / \mathrm{m})$, residential outdoor (urban) $(0.87 \mathrm{~V} / \mathrm{m})$, and library $(0.77 \mathrm{~V} / \mathrm{m})$. Similarly, the five lowest total median exposure levels measured were: residential indoor (rural/suburban) $(0.04 \mathrm{~V} / \mathrm{m})$, residential outdoor (rural/suburban) $(0.07 \mathrm{~V} / \mathrm{m})$, office indoor (urban) $(0.10 \mathrm{~V} / \mathrm{m})$, car (rural/suburban) $(0.11 \mathrm{~V} / \mathrm{m})$, and bicycle (rural/suburban) $(0.12$ $\mathrm{V} / \mathrm{m})$.

\subsection{Comparison of microenvironmental exposures}

Of 17 microenvironmental total exposures measured in each country, only eight microenvironments in Belgium followed lognormal distributions, whereas six followed lognormal and two normal distributions in Australia. The other microenvironmental total exposure data followed neither lognormal nor normal distributions.

The Wilcoxon rank sum tests showed that total exposure for nine microenvironments in Australia were lower than the exposure across the corresponding microenvironments in Belgium $(p<0.05)$ (Table 7). However, the exposure in Australia was found to be higher than the corresponding exposure in Belgium for the five microenvironments $(p<0.05)$ - city center, tram, train, residential outdoor (rural/suburban), and residential indoor (rural/suburban) and the airport. Furthermore, the total exposure levels for the bicycle (urban) and bus 
microenvironments in Australia and Belgium did not show any significant difference. Although the train station microenvironment in Australia provided higher exposure than that in Belgium, the difference was not statistically significant $(p=0.32)$.

The microenvironmental comparisons for total and total DL median exposures in both countries showed strong positive correlations: $r_{s}=0.74(p=0.006)$ for total, and $r_{s}=0.73(p=$ $0.0007)$ for total DL exposures. Furthermore, there were no significant or weak correlations for the total UL and total broadcast exposures $\left(r_{s}=0.086, p=0.74\right.$ for total UL, and $r_{s}=0.46, p=$ 0.06 for total broadcast).

In Australia, total, total DL, and total UL exposures across urban microenvironments were higher than those across rural/suburban microenvironments $(p=0.03)$. However, there was no difference between urban and rural/suburban microenviromental exposures for total broadcast $(p=0.28)$. Nor were there significant differences in total, total DL, total UL and total broadcast exposures between mobile and stationary microenvironments ( $p=0.64$ to 0.90$)$.

In Belgium, total, total DL and total broadcast exposures in urban microenvironments were higher than those in rural/suburban microenvironments $(p=0.006$ for total, $p=0.02$ for total DL, and 0.01 for total broadcast). Whereas there was no difference in the total UL exposure in urban and that in rural/suburban microenvironments $(p=0.09)$. There were no significant differences in total, total DL, total UL and total broadcast exposures between mobile and stationary microenvironments ( $p=0.36$ to 0.96 ).

\subsection{Assessment of the variability in exposures}

Wilcoxon rank sum tests were undertaken to evaluate the repeated measurements of the RFEMF exposure levels. The results have been tabulated in Table 8. Overall, half of the microenvironments (10 of 20 in both countries) showed that repeated measurements provided different total median exposure levels.

Of the 13 microenvironments repeated in Australia, nine showed statistically different total exposure levels at the first and second measurements $(p<0.001-0.04)$ (Table 8$)$, whereas four did not show any significant difference $(p>0.05)$ between the exposure levels. For the tram and residential outdoor (rural/suburban) microenvironments, the total exposures during the two measurement sessions showed little difference, though the $\mathrm{p}$ values were statistically significant.

Of the seven microenvironments repeated in Belgium, six showed statistically different total exposure levels at the first and second measurements $(p<0.001-0.002)$. However, despite having significant $\mathrm{p}$ values, office indoor (urban), residential indoor, and residential outdoor (rural/suburban) provided a little difference in exposure between the first and second measurements. Residential outdoor (urban) did not show statistically significant variation in the exposure levels measured during the repeated measurements $(p=0.16)$.

\section{Discussion}

We have evaluated far-field personal RF-EMF exposures across the different microenvironments in Australia and Belgium by employing two on-body calibrated exposimeters. Measurement of exposures in microenvironments allowed us to: i) identify 
typical exposure levels in the specific microenvironments, ii) monitor exposure trends across these microenvironments over time, and iii) help characterize personal exposure assuming a person occupies a specific microenvironment for a certain amount of time (Dürrenberger et al., 2014). Since most of our exposure data characterized non-normal or non-lognormal distribution, we have preferably presented our results in terms of median and percentiles. Similar presentation of RF-EMF summary statistics have been provided elsewhere (e.g. Bhatt et al., 2016a; Najera et al., 2016). The use of two exposimeters to assess exposure in this study demonstrated that the exposimeters may measure different amounts of RF-EMF signals simultaneously whilst on the body. The proportion of detected signals was high for the mobile phone DL and Wi-Fi bands, which is due to the fact that these signals were relatively common across all microenvironments.

\subsection{Exposure characteristics in Australia and Belgium}

Our study found that mobile phone base downlink exposures contributed the largest share to total exposures (Table 6). Similar results have been reported elsewhere (e.g. Sagar et al., 2016; Urbinello et al., 2014c). The usage of mobile phones and degree of evolution of mobile phone network signals (e.g. GSM 900, GSM 1800, UMTS, and LTE) in Australia and Belgium are not quite the same (International Telecommunication Union, 2010; Kumar, 2004; SpectrumMonitoring, 2016a, 2016b). This perhaps explains the different contribution of frequency band-specific exposures to total RF-EMF exposure in the two countries. We also demonstrated that the concurrent use of two on-body calibrated exposimeters provides exposure levels (for most of the measured frequency bands) nearly up to 2-3 times higher than those provided with a single non-on-body calibrated exposimeter. This is in line with earlier studies (Bolte et al., 2011; Neubauer et al. 2010; Thielens et al. 2015a) that demonstrated that a non-on-body calibrated exposimeter will underestimate personal exposure to incident RF EMFs due to the shielding of the body.

Mobile phone frequency bands of $2600 \mathrm{MHz}$, WiMax $3.5 \mathrm{GHz}$, and ISM $5.8 \mathrm{GHz}$ provided very little exposure. In Melbourne, $2600 \mathrm{MHz}$ has recently been allocated to be used by mobile network providers; however, signals are mostly limited to some urban areas. The band has been officially sold for use in Belgium, but operation has not yet started (SpectrumMonitoring, 2016b). ISM 2.4 GHz shared a small portion of total exposures in both countries (see Table 6), and overall, there was no significant difference between indoor and outdoor microenviromental Wi-Fi 2.4 exposures in either country (results not shown).

Three or four microenvironments in the two countries shared the highest total exposures: the city center, urban parks, and outdoor residential areas. The fourth was a tram station in Belgium, which was located in the city center. The total exposure differences observed across the microenvironments in these two countries may be attributed to the differences in population density and physical infrastructure of Ghent and Melbourne. The exposure difference between the compared microenvironments in both countries was likely to be largely due to the contribution of total downlink exposure, which is generally higher for the microenvironments in Belgium.

The city center, train and airport in Australia (Melbourne) demonstrated higher exposures compared to the corresponding microenvironments in Belgium. Melbourne city center has higher population density and larger number of base stations providing higher capacity of telecommunication signals compared to the Gent city center (OpenSignal, 2016; Antenna Site Register, 2016). The train travels in both countries involved journeys through the respective 
open areas of Melbourne and Ghent. In case of the train travel in Melbourne, high mobile phone signals can occur within the urban region (OpenSignal, 2016), especially with many people on board. Contrary to this, train travel from Ghent to Antwerp, a journey mostly through suburban and rural regions, the strength of RF-EMF signals, particularly of mobile phone base stations was weaker (Antenna Site Register, 2016). The total downlink exposure in the train in Belgium was found to be lower than that in the train in Australia, whereas the total uplink exposure scenario was found to be the opposite. This may be due to a higher path loss between the user and the network, which increases the DL signal that can reach the user and simultaneously increases the UL signal that is necessary to connect to the network. Furthermore, the train in Belgium had windows with metallic coating (Bhatt et al., 2016a), which provided highly attenuated DL signals and the mobile phone has to transmit at a higher power level to get past the metallic coating. Car travel in Australia was done in a less dense urban and suburban area of Melbourne, unlike in Belgium where it was mostly in highly dense urban areas. The resultant lower exposures in Australia for urban car travel were most likely due to this lower urban density.

The total exposure levels, including total DL and total uplink exposures, measured in our study are higher than those reported for similar European microenvironments, including Ghent (Bolte \& Eikelboom, 2012; Joseph et al., 2010; Urbinello et al., 2014a, 2014b, 2014c). This could be because these studies did not correct for the consequence of body shielding on the measured personal exposure levels, which generally underestimates personal exposure levels (Bolte et al., 2011; Neubauer et al. 2010; Thielens et al. 2015a). Our study, however, took this issue into account by using frequency-specific on-body calibration factors while estimating personal exposure levels. Furthermore, these studies used different study protocols (e.g. a single nonon-body calibrated exposimeter), measurement devices and analysis approaches compared to ours. Our study observed that personal exposures in urban microenvironments were much higher than those in rural and suburban microenvironments in Australia and Belgium. Furthermore, the exposure levels across indoor microenvironments were much lower than those across outdoor microenvironments. These findings are in line with of studies conducted in Europe (Bolte \& Eikelboom, 2012; Joseph et al., 2010; Urbinello et al., 2014a, Vermeen et al., 2013). In general, mobile phone base station exposure, the principal contributor to total RFEMF exposure, is generally stronger in urban environments compared to rural and suburban environments (Antenna Site Register, 2016; OpenSignal, 2016; Radio Frequency National Site Archive, 2016). Amongst indoor stationary microenvironments, the library in Belgium and the airport in Australia provided the highest exposure levels. Interestingly, the library in Ghent was about 200 meters from a nearby base station, which was exactly in line-of-sight. This also applied to the tram station in Ghent, which characterized the highest exposure level for outdoor microenvironments in Belgium.

The results demonstrated that total RF-EMF exposure levels varied for the majority of microenvironments in both countries. It is likely that relatively low dispersion of measurements (e.g. residential indoor and residential indoor (rural/suburban) in Belgium) provide statistically significant differences in exposures, without having much differences in median exposures. While comparing these results, we therefore agree that exposure differences should not be solely interpreted on the basis of p-values (The American Statistical Association, 2016). Urbinello et al., (2014c) also showed that the environmental exposure levels of mobile phone DL signals varied across the same areas. Mobile phone DL signals, are the main contributor to the total exposure, and their subsequent variation, has a large effect in the total exposure. In general, diurnal variation in mobile phone signals in human environments is likely due to the variation of spatio-temporal factors (Manassas et al., 2012; Vermeeren et al., 2013; Urbinello 
et al., 2014c). Spatial factors, such as the location of the measurement sites (urban, suburban, rural, outdoor, indoor etc.), the proximity and number of nearby base stations; temporal factors (e.g. day, time and season when the measurements were performed), and existing mobile phone traffic also affect the exposure levels (Bolte \& Eikelboom, 2012; Joseph \& Verloock, 2010; Manassas et al., 2012; Urbinello et al., 2014b; Viel et al., 2009; Vermeeren et al., 2013). The exposure variability in various microenvironments needs to be further examined with much longer measurement times and greater number of repeated measurements with a control of spatio-temporal factors.

All exposure levels measured in our study were well below the reference levels for the general public as provided by the guidelines of the International Commission on Non-Ionizing Radiation Protection (ICNIRP, 1998) and the Australian Radiation Protection and Nuclear Safety Agency (ARPANSA) (Radiation Protection Standard, 2002). However, these guidelines are fundamentally designed to protect against acute (very short-term) RF-EMF health effects, particularly tissue heating. Biological effects have been shown at or below some levels we measured, including decrease in reproductive capacity, apoptotic cell death, and stress responses (Panagopoulos et al., 2010; Augner et al., 2010).

Since most of the exposure data measured in our study did not follow lognormal distributions, we were not able to apply a similar approach to deal with the censored data as used in previous studies (Bolte \& Eikelboom, 2012, Frei et al., 2009, Joseph et al., 2010, Juhász et al., 2011, Urbinello et al., 2014a, Urbinello et al., 2014b). These studies used robust regression on order statistics (ROS) to treat the censored data in order to calculate summary statistics. In addition to ROS, there are other approaches to deal with censored data (i.e. non-detected): substitution, maximum likelihood estimation (MLE) methods, and Kaplan-Meier methods (Ganser \& Hewett, 2010). However, the three most commonly used methods are substitution by LOD, LOD $/ 2$ and LOD $/ \sqrt{ } 2$ (Hewett, 2007, Hewett \& Ganser, 2007). The performance of these methods has been evaluated using simulations on single and contaminated lognormal data and it was found that LOD $/ \sqrt{2}$ substitution method provided slightly positively biased means and negatively biased $95^{\text {th }}$ percentiles, yet plausible results compared to more advanced approaches (Hewett \& Ganser, 2007). Substitution methods have been used in RF-EMF personal exposure assessment elsewhere (Ibrani et al., 2016; Thomas et al., 2008; Röösli et al., 2008).

The evaluation of ROS and substitution (i.e. LOD) methods for RF-EMF exposure generally provided higher values of frequency band-specific summary statistics of exposures (i.e. means, medians, $25^{\text {th }}, 75^{\text {th }}$ and $95^{\text {th }}$ percentiles) compared to the former method (Röösli et al., 2008). Röösli et al. (2008) also observed that the larger the proportion of censored data, the larger was the difference between the substitution (by LOD) and the ROS mean. The frequency-specific LODs for the exposimeter used in our study were lower compared to those employed in previous studies (EME SPY) (Bhatt et al., 2016b), which suggest that our devices were more sensitive than EME SPY.

\subsection{Calibration of the exposimeters}

As shown in Table 2, a majority (12 of 15) of the responses $R$ were lower than 1 , which indicated that the ExpoM-RF underestimated personal exposure in these frequency bands without compensation. The responses in the LTE $2600 \mathrm{MHz}$ and the ISM 2.4 band were close to one. In the ISM 5.8 band, we found an overestimation of exposure by uncorrected measurements. The same underestimation was demonstrated previously (Bolte et al., 2011), where all but one frequency band showed a response $<1$; and Thielens et al. (2015a) showed that all but two frequency bands showed a median response $<1$. 
The PI50 values measured for the ExpoM-RF 64 ranged from 6.3 to $10 \mathrm{~dB}$ and no clear frequency dependence was observed. Thielens et al. (2015a) showed that the PI50 values measured for individual exposimeters worn on the hip ranged from approximately 7 to $13 \mathrm{~dB}$. Bolte et al. (2011) demonstrated these values to be up to approximately $20 \mathrm{~dB}$. The PI50 values are reduced in all frequency bands when an average over two ExpoM-RFs is considered, which is in agreement with previous findings (Thielens et al., 2015a; Bolte et al., 2011). The main reason for this reduction in PI50 is the mirrored RF-EMF pattern of both ExpoM-RFs with regard to the sagittal plane of the subject. For certain azimuthal angles of incidence of RFEMFs, one ExpoM-RF experiences a reduction in received power due to shadowing of the body, while the other ExpoM-RF experiences less or no shadowing at the same time. This consequently results in a more isotropic, average RF-EMF pattern and provides less variation in the distribution of the geometric averaged response.

The high cross-talk shown by the ISM 5.8 band was expected since this frequency band was the highest one, and had the highest potential to register harmonics from lower frequency bands. Similarly, DVB-T induced most cross-talk in other frequency bands, since it was the lowest frequency band. The cross-talk measured DVB-T was closer to a diagonal matrix than the one reported by Thielens et al. (2015a) using another type of exposimeter (EME SPY), where more off-diagonal elements were observed. Though the cross-talk observed in this study was determined using only the central frequencies of the bands, in reality the signals can also be emitted at the edges of the frequency bands and could thus induce a higher cross talk. Therefore, we also calibrated the ExpoM-RF 64 in a free space, using not only the central frequency, but also the two edges of the frequency bands.

The differences in the diagonal elements (shown in Tables 3 and 4, appendix B) were higher than those obtained on the body for the lowest 10 frequency bands and higher than those presented in Table 3 for the five highest frequency bands. This was expected since there was no attenuating body next to the ExpoM-RF in free space. The off-diagonal elements were relatively low in a majority of the cases. Relatively high off-diagonal cross-talk values were measured between LTE 800 DL and DVB-T and between 1800 DL and DECT bands. These values would be expected, since there is a relatively small difference of $1 \mathrm{MHz}$ (LTE $800 \mathrm{DL}$ and DVB-T) and <1 MHz (DECT and $1800 \mathrm{DL}$ ) between the edges of the considered frequency bands, respectively, in comparison to the bandwidth of the considered frequency bands. The highest off-diagonal cross-talk values in these frequency bands were also observed for either the lowest or highest frequency in the studied bands, which indicates that signals can also be emitted close to the edge of a band in reality, the on-body cross-talk values presented in Table 3 (appendix B) might be higher as well. Relatively high off-diagonal cross-talk values were also found in the ISM 5.8 band in Table 4, appendix B. We also observed cross-talk in the onbody matrix in Table 3 (appendix B) in the same frequency band, but with a lower magnitude.

\subsection{Strengths, limitations and implications}

This is the first microenvironmental exposure study to assess far-field RF-EMF exposures from multiple sources across different microenvironments using a pair of on-body calibrated exposimeters. Consequently, our measurements have taken into account body shielding by using frequency-band specific calibration factors or the averaged response of two exposimeters. This means the exposures levels reported in this study provide reduced measurement uncertainties related to body shielding and are corrected for the underestimation caused by the absorption of RF-EMF by the human body. Our study is also the first microenvironmental RF exposure study which evaluated the performance of the used exposimeters was evaluated by 
using cross-talk measurements, which can be used to interpret the measured data. Furthermore, we evaluated exposure in the LTE $2.6 \mathrm{GHz}$, WiMaX $3.5 \mathrm{GHz}$, and ISM 5.8 GHz bands, which were not included in previous studies. Only one recent study (Ibrani et al., 2016), has included evaluation of personal exposures from WiMax $3.5 \mathrm{GHz}$ and ISM 5.8 bands. The exposimeters used in our study are more sensitive than other available and commonly used exposimeters (Bhatt et al., 2016b). The results of this study also allow us to make a valid comparison of the exposure levels across microenvironments in Australia and Belgium, which are characterized by different infrastructure, geophysical, environmental and weather conditions. Therefore, the issue of measurements below the LODs is much less critical, which has been a major challenge in previous exposure assessments (Bolte \& Eikelboom, 2012; Frei et al., 2009; Gajsek et al., 2013; Joseph et al., 2010; Juhász et al., 2011; Thomas et al., 2008, Urbinello et al., 2014b).

However, the study has the following limitations: i) we only involved one site/route per microenvironment and therefore our findings could only provide a conservative estimate for microenvironmental exposure characterization, ii) not all measurements were repeated, iii) each measurement duration was only 15 minutes, iii) assessment of exposure variability involved two measurements (15 min each), and iv) many other sources of RF-EMF exposure in both countries (Australian Radiofrequency Spectrum Plan, 2013; Belgian Institute for Postal services and Telecommunications, 2016; SpectrumMonitoring, 2016) could not be assessed due to the limitation of the measurement device. For instance, AM radio, which is a major source of environmental RF-EMF exposure in Melbourne (Henderson et al., 2014).

We have successfully performed personal far-field RF-EMF exposure assessment using onbody calibrated exposimeters. Therefore the approach contributes towards the development of improved exposure assessment methodology for epidemiological studies. Nevertheless, the application of multiple on-body calibrated exposimeters in epidemiological research may not always be the most rational approach. This is primarily because an on-body calibration is a resource intensive procedure, which is not achievable for large numbers of participants in epidemiological studies. In addition, it is not yet well understood how the results from a limited number of on-body calibrations for a small set of subjects can be translated into a general calibration factor useful for the whole population characterized with different body types (Bhatt et al., 2016a). However, it may still be useful to evaluate calibration factors for various body types, which could potentially be applied in exposure assessment for general populations.

\section{Conclusions}

We measured personal far-field RF-EMF exposure, frequency range $88 \mathrm{MHz}-5.8 \mathrm{GHz}$, in Australia and Belgium across various microenvironments using on-body calibrated exposimeters. Therefore, our study demonstrated that it is feasible to employ two exposimeters concurrently to estimate personal exposure minimizing the consequences of body shielding. Furthermore, our findings suggest that the concurrent use of two on-body calibrated exposimeters provides exposure levels, particularly for mobile phone base stations, DVT-T and DECT, nearly up to 2-3 times higher than those provided with a single non-on-body calibrated exposimeter. This implies that exposure assessment with the use of two on-body calibrated exposimeters has benefits over the use of a single non-on-body calibrated exposimeter and hence recommended, if possible. Mobile phone base downlink exposures contributed the largest share to total exposures. Of 17 microenvironments compared, nine of them provided lower exposure levels in Melbourne (Australia) than the corresponding microenvironments in Ghent (Belgium). The personal exposures across urban microenvironments were lower than 
those in rural and suburban microenvironments. Similarly, exposure levels found across indoor microenvironments were lower than outdoors.

Further studies are needed to provide more accurate exposure characterization considering multiple sites/routes per microenvironment.

\section{Acknowledgements}

This research was supported by the Centre for Population Health Research on Electromagnetic Energy (PRESEE), School of Public Health and Preventive Medicine, Monash University. The center is funded by a grant from the National Health and Medical Research Council, Australia (APP 1060205). Arno Thielens is a post-doctoral fellow of Flanders Innovation and Entrepreneurship under agreement no 150752.

The authors would like to thank: i) Matthias Van den Bossche and Leen Verloock for their technical support, ii) Dr Suman Bajracharya, Dr Fabricio Fiengo Perez, Dr David Goddard and Dr Diogenes Seraphim Ferreira for their kind help in carrying out field measurements employing car and bicycle.

\section{REFERENCES}

Antenna Site Register, 2016. http://www.sites.bipt.be/index.php?language=EN. Accessed on 25.02.2016.

Australian Radiofrequency Spectrum Plan, 2013. Australian Communications and Media Authority. http://www.acma.gov.au/ /media/Spectrum\%20Transformation\%20and\%20Governm ent/Information/pdf/Australian\%20Radiofrequency\%20Spectrum\%20Plan\%202013.p df Accessed on 29.02.2016.

Augner, C., Hacker, G.W., Oberfeld, G., Florian, M., Hitzl, W., Hutter, J., Pauser, G., 2010. Effects of exposure to GSM mobile phone base station signals on salivary cortisol, alpha-amylase, and immunoglobulin A. Biomed Environ Sci. 23,199-207.

Baan, R., Grosse, Y., Lauby-Secretan, B., El Ghissassi, F., Bouvard, V., Benbrahim-Tallaa, L., Guha, N., Islami, F., Galichet, L., Straif, K. 2011. Carcinogenicity of radiofrequency electromagnetic fields. Lancet Oncol. 12, 624-626.

Belgian Institute for Postal services and Telecommunications, 2016. http://www.bipt.be/en/operators/radio/frequency-management/frequency-plan/table Accessed on 29.02.2016.

Bhatt, C.R., Thielens, A., Redmayne, M., Abramson, M.J., Billah, B., Sim, M.R., Vermeulen, R., Martens, L., Joseph, W., Benke, G. 2016a. Measuring personal exposure from 900 $\mathrm{MHz}$ mobile phone base stations in australia and belgium using a novel personal distributed exposimeter. Environ. Int. 92-93, 388-397.

Bhatt, C.R., Redmayne, M., Abramson, M.J., Benke, G., 2016b. Instruments to assess and measure personal and environmental radiofrequency-electromagnetic field exposures. Australas Phys. Eng. Sci. Med. 39, 29-42.

Bolte, J.F., van der Zande, G., Kamer, J., 2011. Calibration and uncertainties in personal exposure measurements of radiofrequency electromagnetic fields. Bioelectromagnetics 32, 652-663. 
Bolte, J.F.B., Eikelboom, T., 2012. Personal radiofrequency electromagnetic field measurements in the Netherlands: Exposure level and variability for everyday activities, times of day and types of area. Environ Int. 48,133-142.

Dürrenberger, G., Fröhlich, J., Röösli, M., Mattsson, M.O., 2014. EMF monitoringconcepts, activities, gaps and options. Int J Environ Res Public Health 11, 9460-9479.

Frei, P., Mohler, E., Neubauer, G., Theis, G., Burgi, A., Frohlich, J., Braun-Fahrlander, C., Bolte, J., Egger, M., Röösli, M., 2009. Temporal and spatial variability of personal exposure to radio frequency electromagnetic fields. Environ Res. 109, 779-785.

Gajšek, P., Ravazzani, P., Wiart, J., Grellier, J., Samaras, T.,Thuróczy, G., 2015. Electromagnetic field exposure assessment in Europe radiofrequency fields (10 MHz$6 \mathrm{GHz}$ ). J Expo Sci Environ Epidemiol. 25, 37-44.

Ganser, G.H., Hewett, P., 2010. An accurate substitution method for analyzing censored data. J Occup Environ Hyg. 7, 233-244.

Henderson, S., Tjong, L., Wijayasinghe, D., 2014. Survey of radiofrequency radiation levels across Melbourne. Proc. of the $39^{\text {th }}$ Australasian Radiation Protection Society Conference,Hobart, 26-29 June 2014.

Henderson, S., Bangay, M., 2006. Survey of RF exposure levels from mobile telephone base stations in Australia. Bioelectromagnetics 27, 73-76.

Hewett, P., Ganser, G.H., 2007. A comparison of several methods for analyzing censored data. Ann Occup Hyg. 51,611-632.

Ibrani, M., Hamiti, E., Ahma, L., Shala B., 2016. Assessment of personal radio frequency electromagnetic fieldexposure in specific indoor workplaces and possibleworst-case scenarios. International Journal of Electronics and Communications, 70, 808-813. doi:10.1016/j.aeue.2016.03.007.

ICNIRP, 1998. The International Commission on Non-ionizing Radiation Protection. Guidelines for limiting exposure to time-varying electric, magnetic, and electromagnetic fields ( up to $300 \mathrm{GHz}$ ). Health Phys. 74 (4), 494-522.

International Telecommunication Union, 2010. The evolution to 3G mobile - status report. https://www.itu.int/itunews/issue/2003/06/thirdgeneration.html Accessed on 27.02.2016.

Iskra, S., McKenzie, R.J., Cosic, I., 2011. Monte Carlo simulations of the electric field close to the body in realistic environments for application in personal radiofrequency dosimetry. Radiat Prot Dosimetry 147, 517-527.

Joseph, W., Frei, P., Röösli, M., Thuróczy, G., Gajšek, P., Trcek, T., Bolte, J., Vermeeren, G., Mohler, E., Juhász, P., Finta, V., Martens, L., 2010. Comparison of personal radio frequency electromagnetic field exposure in different urban areas across Europe. Environ Res. 110, 658-663.

Joseph, W., Verloock, L., 2010. Influence on mobile phone traffic on base station exposure of the general public. Health Phys. 99(5), 631-638.

Juhász, P., Bakos, J., Nagy, N., Jánossy, G., Finta, V, Thuróczy, G., 2011. RF personal exposimetry on employees of elementary schools, kindergartens and day nurseries as a proxy for child exposures. Prog Biophys Mol Biol. 107, 449-455.

Kumar, S., 2004. Mobile communications: Global trends in the 21 st century. Int J Mobile Communication 2, 67-86.

Mann, S., 2010. Assessing personal exposures to environmental radiofrequency electromagnetic fields. Comptes Rendus Physique. 11, 541-555.

Manassas, A., Boursianis, A., Samaras, T., Sahalos, J.N., 2012. Continuous electromagnetic radiation monitoring in the environment: analysis of the results in Greece. Radiat Prot Dosimetry 151(3), 437-442. 
Najera, A., Gonzalez-Rubio, J., Arribas E., 2016. Stastistical analysis of nondetects consideration in personal exposition to RF-EMF measurements [poster]. The BioEM conference, Ghent, 5-10 June 2016.

Neubauer, G., Cecil, S., Giczi, W., Petric, B., Preiner, P., Fröhlich, J., Röösli M., 2008. Final Report on the project C2006-07: evaluation of the correlation between RF dosimeter reading and real human exposure ARC-IT-0218. http://www.emf.ethz.ch/archive/var/SB_Neubaue_pre25f.pdf Accessed on 22.06.2016.

Neubauer, G., Cecil, S., Giczi, W., Petric, B., Preiner, P., Fröhlich, J., Röösli, M., 2010. The association between exposure determined by radiofrequency personal exposimeters and human exposure: a simulation study. Bioelectromagnetics 31, 535-545.

OpenSignal, 2016. http://opensignal.com/ Accessed on 25.02.2016.

Panagopoulos, D.J., Chavdoula, E.D., Margaritis, L.H., 2010. Bioeffects of mobile telephony radiation in relation to its intensity or distance from the antenna. Int $\mathrm{J}$ Radiat Biol. 86, 345-357.

Radiation Protection Standard, 2002. Maximum Exposure Levels to Radiofrequency Fields $3 \mathrm{kHz}$ to $300 \mathrm{GHz}$. Radiation Protection Series Publication No. 3. the Australian Radiation Protection and Nuclear Safety Agency, pp 1-128.

Radio Frequency National Site Archive, 2016. http://www.rfnsa.com.au/nsa/index.cgi?type=logout Accessed on 25.02.2016.

Röösli, M., Frei, P., Mohler, E., Braun-Fahrlander, C., Burgi, A., Frohlich, J., Neubauer, G., Theis, G., Egger, M., 2008. Statistical analysis of personal radiofrequency electromagnetic field measurements with nondetects. Bioelectromagnetics 29, 471478.

Röösli, M., Frei, P., Bolte, J., Neubauer, G., Cardis, E., Feychting, M., Gajsek, P., Heinrich, S., Joseph, W., Mann, S., Martens, L., Mohler, E., Parslow, R.C., Poulsen, A.H., Radon, K., Schuz, J., Thuroczy, G., Viel, J.F.,Vrijheid, M., 2010. Conduct of a personal radiofrequency electromagnetic field measurement study: proposed study protocol. Environ Health. 9, 23, 1-14.

Rowley, J.T., Joyner, K.H., 2012. Comparative international analysis of radiofrequency exposure surveys of mobile communication radio base stations. J Expo Sci Environ Epidemiol. 22, 304-315.

Sagar, S., Struchen, B., Finta, V., Eeftens, M., Röösli, M., 2016. Use of portable exposimeters to monitor radiofrequency electromagnetic field exposure in the everyday environment. Environ Res. 150, 289-298. doi:10.1016/j.envres.2016.06.020.

SpectrumMonitoring, 2016 . http://www.spectrummonitoring.com/frequencies/frequencies3.html\#Australia Accessed on 18.03.2016.

SpectrumMonitoring, $2016 \mathrm{~b}$. http://www.spectrummonitoring.com/frequencies/index.html\#Belgium. Accessed on 18.03.2016.

The American Statistical Association, 2016. The ASA statement on statistitical significance and P-values. February 5, 2016. Edited by Ronald L. Wasserstein, Executive Director. Thielens, A., Agneessens, S., Verloock, L., Tanghe, E., Rogier, H., Martens, L., Joseph, W., 2015a. On-body calibration and processing for a combination of two radio-frequency personal exposimeters. Radiat Prot Dosimetry 163, 58-69.

Thielens, A., Agneessens, S., De Clercq, H., Lecoutere, J., Verloock, L., Tanghe, E., Aerts, S., Puers, R., Rogier, H., Martens, L., Joseph, W. 2015b. On-body Calibration and 
Measurements using a Personal, Distributed Exposimeter for Wireless Fidelity. Health Phys. 108(4), 407-418.

Thielens, A., De Clercq, H., Agneessens, S., Lecoutere, J., Verloock, L., Declercq, F., Vermeeren, G., Tanghe, E., Rogier, H., Puers, R., 2013. Personal distributed exposimeter for radio frequency exposure assessment in real environments. Bioelectromagnetics 34, 563-567.

Thomas, S., Kühnlein, A., Heinrich, S., Praml, G., von Kries, R., Radon, K., 2008. Exposure to mobile telecommunication networks assessed using personal dosimetry and wellbeing in children and adolescents: the German MobilEe-study. Environ Health. 4;7, 54. doi: 10.1186/1476-069X-7-54.

Urbinello, D., Joseph, W., Verloock, L., Martens, L., Röösli, M., 2014a. Temporal trends of radio-frequency electromagnetic field (RF-EMF) exposure in everyday environments across European cities. Environ Res. 134, 134-142.

Urbinello, D., Joseph, W., Huss, A., Verloock, L., Beekhuizen, J., Vermeulen, R., Martens, L., Röösli, M., 2014b. Radio-frequency electromagnetic field (RF-EMF) exposure levels in different European outdoor urban environments in comparison with regulatory limits. Environ Int. 68, 49-54.

Urbinello, D., Huss, A., Beekhuizen, J., Vermeulen, R., Röösli, M., 2014c. Use of portable exposure meters for comparing mobile phone base station radiation in different types of areas in the cities of Basel and Amsterdam. Sci Total Environ. 468-469:10281033.

van Deventer, E., van Rongen, E., Saunders, R., 2011. WHO research agenda for radiofrequency fields. Bioelectromagnetics 32, 417-421.

Vanveerdeghem, P., Vantorre, P., Thielens, A., Knockaert, J., Joseph, W., Rogier, H. 2015. Compact Personal Distributed Wearable Exposimeter. IEEE Sensors Journal 15(8), 4393-4401.

Vermeeren, G., Markakis, I., Goeminne, F., Samaras, T., Martens, L., Joseph, W., 2013. Spatial and temporal RF electromagnetic field exposure of children and adults in indoor micro environments in Belgium and Greece. Prog Biophys Mol Biol. 113, 254-263.

Viel, J.F., Clerc, S., Barrera, C., Rymzhanova, R., Moissonnier, M., Hours, M., Cardis, E., 2009. Residential exposure to radiofrequency fields from mobile phone base stations, and broadcast transmitters: a population-based survey with personal meter. Occup Environ Med. 66, 550-556. 


\section{Appendix A}

Table 1. Proportion of measured data (\%) falling below the LODs of ExpoM-RFs across various microenvironments in Australia and Belgium

Proportion of measured data (\%) below the detection thresholds (measurement 1, measurement 2)

\begin{tabular}{|c|c|c|c|c|c|c|c|c|c|c|c|c|c|c|c|c|c|c|}
\hline Microenvironments & Countries & $\begin{array}{l}\text { ExpoM- } \\
\text { RF IDs }\end{array}$ & FM & $\begin{array}{l}\text { DVT- } \\
\text { T }\end{array}$ & $\begin{array}{l}\text { LTE } \\
800 \\
\text { DL }\end{array}$ & $\begin{array}{l}\text { LTE } 800 \\
\text { UL }\end{array}$ & $\begin{array}{l}\text { GSM } \\
900 \\
\text { UL }\end{array}$ & $\begin{array}{l}\text { GSM } \\
900 \\
\text { DL }\end{array}$ & $\begin{array}{l}\text { GSM } \\
1800 \text { UL }\end{array}$ & $\begin{array}{l}\text { GSM } \\
1800 \\
\text { DL }\end{array}$ & DECT & $\begin{array}{l}\text { UMTS } \\
\text { UL }\end{array}$ & $\begin{array}{l}\text { UMTS } \\
\text { DL }\end{array}$ & $\begin{array}{l}\text { ISM } \\
2.4\end{array}$ & $\begin{array}{l}\text { LTE } 2600 \\
\text { UL }\end{array}$ & $\begin{array}{l}\text { LTE } \\
2600 \text { DL }\end{array}$ & $\begin{array}{l}\text { WiMax } \\
3.5\end{array}$ & ISM 5.8 \\
\hline \multirow[t]{2}{*}{$\begin{array}{l}\text { Residential outdoor } \\
\text { (urban) }\end{array}$} & Australia & $\begin{array}{l}40 \\
64\end{array}$ & $\begin{array}{l}73,76 \\
58,68\end{array}$ & $\begin{array}{l}0,0 \\
4,0\end{array}$ & $\begin{array}{l}40,49 \\
31,36\end{array}$ & $\begin{array}{l}75,78 \\
10,37\end{array}$ & $\begin{array}{l}0,0 \\
0,0\end{array}$ & $\begin{array}{l}0,0 \\
0,0\end{array}$ & $\begin{array}{l}68,91 \\
68,89\end{array}$ & $\begin{array}{l}0,0 \\
0,0\end{array}$ & $\begin{array}{l}0,0 \\
0,0\end{array}$ & $\begin{array}{l}96,99 \\
96,99\end{array}$ & $\begin{array}{l}0,0 \\
0,0\end{array}$ & $\begin{array}{l}9,19 \\
0,0\end{array}$ & $\begin{array}{l}99,100 \\
100,100\end{array}$ & $\begin{array}{l}16,7 \\
16,9\end{array}$ & $\begin{array}{l}99,99 \\
93,97\end{array}$ & $\begin{array}{l}53,81 \\
63,89\end{array}$ \\
\hline & Belgium & $\begin{array}{l}40 \\
64\end{array}$ & $\begin{array}{l}7,0 \\
3,0\end{array}$ & $\begin{array}{l}0,0 \\
3,0\end{array}$ & $\begin{array}{l}93,99 \\
97,96\end{array}$ & $\begin{array}{l}16,8 \\
0,0\end{array}$ & $\begin{array}{l}95,91 \\
91,83\end{array}$ & $\begin{array}{l}0,0 \\
0,0\end{array}$ & $\begin{array}{l}41,36 \\
95,76\end{array}$ & $\begin{array}{l}0,0 \\
0,0\end{array}$ & $\begin{array}{l}0,0 \\
6,0\end{array}$ & $\begin{array}{l}99,98 \\
99,98\end{array}$ & $\begin{array}{l}0,0 \\
0,0\end{array}$ & $\begin{array}{l}0,0 \\
0,0\end{array}$ & $\begin{array}{l}100,100 \\
100,100\end{array}$ & $\begin{array}{l}100,100 \\
100,100\end{array}$ & $\begin{array}{l}100,98 \\
100,100\end{array}$ & $\begin{array}{l}54,50 \\
85,8\end{array}$ \\
\hline \multirow[t]{2}{*}{$\begin{array}{l}\text { Residential indoor } \\
\text { (urban) }\end{array}$} & Australia & $\begin{array}{l}40 \\
64 \\
\end{array}$ & $\begin{array}{l}100,100 \\
100,100\end{array}$ & $\begin{array}{l}99,4 \\
84,40 \\
\end{array}$ & $\begin{array}{l}99,100 \\
97,99 \\
\end{array}$ & $\begin{array}{l}96,97 \\
72,15 \\
\end{array}$ & $\begin{array}{l}0,0 \\
0,0\end{array}$ & $\begin{array}{l}0,0 \\
0,0\end{array}$ & $\begin{array}{l}97,99 \\
97,99 \\
\end{array}$ & $\begin{array}{l}0,0 \\
0,0\end{array}$ & $\begin{array}{l}4,7 \\
19,11 \\
\end{array}$ & $\begin{array}{l}99,99 \\
99,99 \\
\end{array}$ & $\begin{array}{l}0,0 \\
0,0\end{array}$ & $\begin{array}{l}9,21 \\
0,0 \\
\end{array}$ & $\begin{array}{l}100,100 \\
100,100 \\
\end{array}$ & $\begin{array}{l}0,0 \\
0,0 \\
\end{array}$ & $\begin{array}{l}100,100 \\
100,100 \\
\end{array}$ & $\begin{array}{l}100,100 \\
100,100\end{array}$ \\
\hline & Belgium & $\begin{array}{l}40 \\
64 \\
\end{array}$ & $\begin{array}{l}14,3 \\
17,1 \\
\end{array}$ & $\begin{array}{l}3,0 \\
23,12 \\
\end{array}$ & $\begin{array}{l}100,32 \\
100,8 \\
\end{array}$ & $\begin{array}{l}20,8 \\
0,0 \\
\end{array}$ & $\begin{array}{l}96,98 \\
97,98 \\
\end{array}$ & $\begin{array}{l}0,0 \\
0,0 \\
\end{array}$ & $\begin{array}{l}94,98 \\
99,98 \\
\end{array}$ & $\begin{array}{l}0,0 \\
0,0 \\
\end{array}$ & $\begin{array}{l}24,9 \\
89,18 \\
\end{array}$ & $\begin{array}{l}100,100 \\
100,100 \\
\end{array}$ & $\begin{array}{l}0,0 \\
0,0 \\
\end{array}$ & $\begin{array}{l}0,0 \\
0,0 \\
\end{array}$ & $\begin{array}{l}100,98 \\
100,100\end{array}$ & $\begin{array}{l}100,100 \\
100,100 \\
\end{array}$ & $\begin{array}{l}100,100 \\
99,100 \\
\end{array}$ & $\begin{array}{l}100,100 \\
99,100\end{array}$ \\
\hline \multirow[t]{2}{*}{ Office indoor (urban) } & Australia & $\begin{array}{l}40 \\
64 \\
\end{array}$ & $\begin{array}{l}88,98 \\
99,100\end{array}$ & $\begin{array}{l}38,40 \\
44,44\end{array}$ & $\begin{array}{l}83,97 \\
58,46 \\
\end{array}$ & $\begin{array}{l}97,100 \\
80,70 \\
\end{array}$ & $\begin{array}{l}34,45 \\
7,41 \\
\end{array}$ & $\begin{array}{l}0,0 \\
0,0\end{array}$ & $\begin{array}{l}92,69 \\
95,79\end{array}$ & $\begin{array}{l}2,4 \\
3,13 \\
\end{array}$ & $\begin{array}{l}68,48 \\
80,48\end{array}$ & $\begin{array}{l}33,40 \\
32,45 \\
\end{array}$ & $\begin{array}{l}0,0 \\
0,1\end{array}$ & $\begin{array}{l}7,5 \\
0,0 \\
\end{array}$ & $\begin{array}{l}100,100 \\
100,100\end{array}$ & $\begin{array}{l}87,86 \\
68,48 \\
\end{array}$ & $\begin{array}{l}100,100 \\
100,100\end{array}$ & $\begin{array}{l}100,100 \\
100,100\end{array}$ \\
\hline & Belgium & $\begin{array}{l}40 \\
64 \\
\end{array}$ & $\begin{array}{l}94,83 \\
85,86 \\
\end{array}$ & $\begin{array}{l}79,64 \\
100,99 \\
\end{array}$ & $\begin{array}{l}82,66 \\
81,59 \\
\end{array}$ & $\begin{array}{l}18,51 \\
3,3 \\
\end{array}$ & $\begin{array}{l}58,77 \\
52,76 \\
\end{array}$ & $\begin{array}{l}0,0 \\
0,0\end{array}$ & $\begin{array}{l}76,64 \\
80,70 \\
\end{array}$ & $\begin{array}{l}15,26 \\
18,20 \\
\end{array}$ & $\begin{array}{l}23,31 \\
25,29 \\
\end{array}$ & $\begin{array}{l}74,66 \\
74,64 \\
\end{array}$ & $\begin{array}{l}6,16 \\
8,16 \\
\end{array}$ & $\begin{array}{l}4,8 \\
0,0 \\
\end{array}$ & $\begin{array}{l}85,100 \\
78,100 \\
\end{array}$ & $\begin{array}{l}97,100 \\
96,100 \\
\end{array}$ & $\begin{array}{l}100,100 \\
97,100\end{array}$ & $\begin{array}{l}44,71 \\
68,83 \\
\end{array}$ \\
\hline \multirow[t]{2}{*}{ Park (urban) } & Australia & $\begin{array}{l}40 \\
64 \\
\end{array}$ & $\begin{array}{l}82,96 \\
67,90 \\
\end{array}$ & $\begin{array}{l}0,0 \\
0,0 \\
\end{array}$ & $\begin{array}{l}5,0 \\
0,0 \\
\end{array}$ & $\begin{array}{l}55,41 \\
0,10 \\
\end{array}$ & $\begin{array}{l}0,0 \\
0,0 \\
\end{array}$ & $\begin{array}{l}0,0 \\
0,0 \\
\end{array}$ & $\begin{array}{l}92,93 \\
94,96 \\
\end{array}$ & $\begin{array}{l}0,0 \\
0,0 \\
\end{array}$ & $\begin{array}{l}0,0 \\
0,0 \\
\end{array}$ & $\begin{array}{l}100,99 \\
99,99 \\
\end{array}$ & $\begin{array}{l}0,0 \\
0,0 \\
\end{array}$ & $\begin{array}{c}34,19 \\
0,0 \\
\end{array}$ & $\begin{array}{l}100,100 \\
100,100 \\
\end{array}$ & $\begin{array}{l}1,1 \\
0,0 \\
\end{array}$ & $\begin{array}{l}99,97 \\
98,95 \\
\end{array}$ & $\begin{array}{l}75,62 \\
94,92 \\
\end{array}$ \\
\hline & Belgium & $\begin{array}{l}40 \\
64 \\
\end{array}$ & $\begin{array}{l}0,0 \\
1,0 \\
\end{array}$ & $\begin{array}{l}0,0 \\
0,0\end{array}$ & $\begin{array}{l}99,96 \\
100,98\end{array}$ & $\begin{array}{l}0,0 \\
0,0 \\
\end{array}$ & $\begin{array}{l}92,92 \\
90,88 \\
\end{array}$ & $\begin{array}{l}0,0 \\
0,0 \\
\end{array}$ & $\begin{array}{l}87,85 \\
93,90 \\
\end{array}$ & $\begin{array}{l}0,0 \\
0,0\end{array}$ & $\begin{array}{l}0,0 \\
6,0 \\
\end{array}$ & $\begin{array}{l}99,98 \\
100,99 \\
\end{array}$ & $\begin{array}{l}0,0 \\
0,0 \\
\end{array}$ & $\begin{array}{l}35,13 \\
0,0 \\
\end{array}$ & $\begin{array}{l}100,100 \\
100,100 \\
\end{array}$ & $\begin{array}{l}100,100 \\
100,100 \\
\end{array}$ & $\begin{array}{l}54,21 \\
34,13 \\
\end{array}$ & $\begin{array}{l}94,81 \\
98,93 \\
\end{array}$ \\
\hline \multirow[t]{2}{*}{ City centre } & Australia & $\begin{array}{l}40 \\
64 \\
\end{array}$ & $\begin{array}{l}0,0 \\
0,0\end{array}$ & $\begin{array}{l}0,0 \\
0,0\end{array}$ & $\begin{array}{l}0,0 \\
0,0\end{array}$ & $\begin{array}{l}25,47 \\
0,0\end{array}$ & $\begin{array}{l}0,0 \\
0,0\end{array}$ & $\begin{array}{l}0,0 \\
0,0\end{array}$ & $\begin{array}{l}0,0 \\
0,0 \\
\end{array}$ & $\begin{array}{l}0,0 \\
0,0\end{array}$ & $\begin{array}{l}0,0 \\
0,0\end{array}$ & $\begin{array}{l}30,39 \\
85,84 \\
\end{array}$ & $\begin{array}{l}0,0 \\
0,0\end{array}$ & $\begin{array}{l}0,0 \\
0,0\end{array}$ & $\begin{array}{l}29,71 \\
1,6\end{array}$ & $\begin{array}{l}0,0 \\
0,0\end{array}$ & $\begin{array}{l}5,17 \\
2,10 \\
\end{array}$ & $\begin{array}{l}0,0 \\
0,0 \\
\end{array}$ \\
\hline & Belgium & $\begin{array}{l}40 \\
64 \\
\end{array}$ & $\begin{array}{l}0,0 \\
0,0 \\
\end{array}$ & $\begin{array}{l}0,0 \\
0,0 \\
\end{array}$ & $\begin{array}{l}66,90 \\
67,87 \\
\end{array}$ & $\begin{array}{l}0,0 \\
0,0 \\
\end{array}$ & $\begin{array}{l}57,53 \\
38,33 \\
\end{array}$ & $\begin{array}{l}0,0 \\
0,0\end{array}$ & $\begin{array}{l}17,33 \\
16,40 \\
\end{array}$ & $\begin{array}{l}0,0 \\
0,0\end{array}$ & $\begin{array}{l}0,4 \\
0,3 \\
\end{array}$ & $\begin{array}{l}97,92 \\
97,88 \\
\end{array}$ & $\begin{array}{l}0,0 \\
0,0\end{array}$ & $\begin{array}{l}0,1 \\
0,0\end{array}$ & $\begin{array}{l}100,100 \\
100,100 \\
\end{array}$ & $\begin{array}{l}100,100 \\
100,100 \\
\end{array}$ & $\begin{array}{l}89,70 \\
74,38 \\
\end{array}$ & $\begin{array}{l}53,89 \\
64,95 \\
\end{array}$ \\
\hline \multirow[t]{2}{*}{ Library (urban) } & Australia & $\begin{array}{l}40 \\
64 \\
\end{array}$ & $\begin{array}{l}98,94 \\
99,96 \\
\end{array}$ & $\begin{array}{l}14,13 \\
88,76 \\
\end{array}$ & $\begin{array}{l}99,99 \\
69,80 \\
\end{array}$ & $\begin{array}{l}100,100 \\
100,100\end{array}$ & $\begin{array}{l}1,3 \\
0,0\end{array}$ & $\begin{array}{l}0,0 \\
0,0\end{array}$ & $\begin{array}{l}92,81 \\
94,91 \\
\end{array}$ & $\begin{array}{l}2,0 \\
4,0\end{array}$ & $\begin{array}{l}13,14 \\
26,42 \\
\end{array}$ & $\begin{array}{l}80,77 \\
80,81 \\
\end{array}$ & $\begin{array}{l}0,1 \\
0,0\end{array}$ & $\begin{array}{l}1,7 \\
0,0\end{array}$ & $\begin{array}{l}100,100 \\
100,100 \\
\end{array}$ & $\begin{array}{l}100,100 \\
100,100 \\
\end{array}$ & $\begin{array}{l}100,100 \\
100,100\end{array}$ & $\begin{array}{l}98,94 \\
99,97 \\
\end{array}$ \\
\hline & *Belgium & $\begin{array}{l}40 \\
64 \\
\end{array}$ & $\begin{array}{l}0 \\
0 \\
\end{array}$ & $\begin{array}{l}0 \\
0 \\
\end{array}$ & $\begin{array}{l}99 \\
99 \\
\end{array}$ & $\begin{array}{l}0 \\
0 \\
\end{array}$ & $\begin{array}{l}96 \\
90 \\
\end{array}$ & $\begin{array}{l}0 \\
0 \\
\end{array}$ & $\begin{array}{l}84 \\
91 \\
\end{array}$ & $\begin{array}{l}0 \\
0 \\
\end{array}$ & $\begin{array}{l}0 \\
0 \\
\end{array}$ & $\begin{array}{l}97 \\
100 \\
\end{array}$ & $\begin{array}{l}0 \\
0 \\
\end{array}$ & $\begin{array}{l}0 \\
0 \\
\end{array}$ & $\begin{array}{l}100 \\
100 \\
\end{array}$ & $\begin{array}{l}100 \\
100\end{array}$ & $\begin{array}{l}2 \\
1 \\
\end{array}$ & $\begin{array}{l}67 \\
35 \\
\end{array}$ \\
\hline \multirow[t]{2}{*}{$\begin{array}{l}\text { Shopping centre } \\
\text { (urban) }\end{array}$} & Australia & $\begin{array}{l}40 \\
64\end{array}$ & $\begin{array}{l}99,98 \\
99,96\end{array}$ & $\begin{array}{l}73,52 \\
73,60\end{array}$ & $\begin{array}{l}60,55 \\
56,40\end{array}$ & $\begin{array}{l}99,99 \\
98,83\end{array}$ & $\begin{array}{l}71,35 \\
64,18 \\
\end{array}$ & $\begin{array}{l}0,0 \\
0,0\end{array}$ & $\begin{array}{l}69,27 \\
71,50\end{array}$ & $\begin{array}{l}66,66 \\
65,65\end{array}$ & $\begin{array}{l}85,90 \\
82,91\end{array}$ & $\begin{array}{l}68,61 \\
66,60\end{array}$ & $\begin{array}{l}31,43 \\
32,41\end{array}$ & $\begin{array}{l}0,5 \\
0,0\end{array}$ & $\begin{array}{l}99,100 \\
98,99\end{array}$ & $\begin{array}{l}79,84 \\
55,59\end{array}$ & $\begin{array}{l}100,100 \\
100,100\end{array}$ & $\begin{array}{l}100,100 \\
100,100 \\
\end{array}$ \\
\hline & "Belgium & $\begin{array}{l}40 \\
64\end{array}$ & $\begin{array}{l}5 \\
11\end{array}$ & $\begin{array}{l}12 \\
54\end{array}$ & $\begin{array}{l}59 \\
44\end{array}$ & $\begin{array}{l}44 \\
5\end{array}$ & $\begin{array}{l}8 \\
5\end{array}$ & $\begin{array}{l}0 \\
0\end{array}$ & $\begin{array}{l}26 \\
33\end{array}$ & $\begin{array}{l}5 \\
7\end{array}$ & $\begin{array}{l}6 \\
8\end{array}$ & $\begin{array}{l}10 \\
6\end{array}$ & $\begin{array}{l}3 \\
4\end{array}$ & $\begin{array}{l}0 \\
0\end{array}$ & $\begin{array}{l}100 \\
100\end{array}$ & $\begin{array}{l}100 \\
100\end{array}$ & $\begin{array}{l}97 \\
97\end{array}$ & $\begin{array}{l}99 \\
100\end{array}$ \\
\hline \multirow[t]{2}{*}{ Train station (urban) } & Australia & $\begin{array}{l}40 \\
64 \\
\end{array}$ & $\begin{array}{l}85,99 \\
91,91 \\
\end{array}$ & $\begin{array}{l}0,0 \\
0,0 \\
\end{array}$ & $\begin{array}{l}0,10 \\
0,0 \\
\end{array}$ & $\begin{array}{l}100,100 \\
93,91\end{array}$ & $\begin{array}{l}0,0 \\
0,0 \\
\end{array}$ & $\begin{array}{l}0,0 \\
0,0 \\
\end{array}$ & $\begin{array}{l}8,24 \\
49,43 \\
\end{array}$ & $\begin{array}{l}0,0 \\
0,0 \\
\end{array}$ & $\begin{array}{l}0,0 \\
0,0 \\
\end{array}$ & $\begin{array}{l}52,56 \\
48,50 \\
\end{array}$ & $\begin{array}{l}0,0 \\
0,0 \\
\end{array}$ & $\begin{array}{l}0,0 \\
0,0 \\
\end{array}$ & $\begin{array}{l}94,96 \\
89,99 \\
\end{array}$ & $\begin{array}{l}3,0 \\
0,1 \\
\end{array}$ & $\begin{array}{l}100,100 \\
100,100 \\
\end{array}$ & $\begin{array}{l}14,29 \\
48,66 \\
\end{array}$ \\
\hline & "Belgium & $\begin{array}{l}40 \\
64\end{array}$ & $\begin{array}{l}1 \\
3 \\
\end{array}$ & $\begin{array}{l}1 \\
4 \\
\end{array}$ & $\begin{array}{l}77 \\
51 \\
\end{array}$ & $\begin{array}{l}56 \\
13 \\
\end{array}$ & $\begin{array}{l}13 \\
9 \\
\end{array}$ & $\begin{array}{l}0 \\
0 \\
\end{array}$ & $\begin{array}{l}31 \\
38 \\
\end{array}$ & $\begin{array}{l}1 \\
8 \\
\end{array}$ & $\begin{array}{l}17 \\
22 \\
\end{array}$ & $\begin{array}{l}46 \\
50 \\
\end{array}$ & $\begin{array}{l}0 \\
0 \\
\end{array}$ & $\begin{array}{l}9 \\
0 \\
\end{array}$ & $\begin{array}{l}98 \\
100 \\
\end{array}$ & $\begin{array}{l}100 \\
100 \\
\end{array}$ & $\begin{array}{l}81 \\
55 \\
\end{array}$ & $\begin{array}{l}77 \\
81 \\
\end{array}$ \\
\hline Tram station (urban) & Australia & $\begin{array}{l}40 \\
64 \\
\end{array}$ & $\begin{array}{l}84,59 \\
79,48 \\
\end{array}$ & $\begin{array}{l}0,0 \\
0,0 \\
\end{array}$ & $\begin{array}{l}3,2 \\
0,0 \\
\end{array}$ & $\begin{array}{l}31,38 \\
0,0 \\
\end{array}$ & $\begin{array}{l}0,0 \\
0,0 \\
\end{array}$ & $\begin{array}{l}0,0 \\
0,0 \\
\end{array}$ & $\begin{array}{l}71,72 \\
82,80 \\
\end{array}$ & $\begin{array}{l}0,0 \\
0,0 \\
\end{array}$ & $\begin{array}{l}0,0 \\
0,0 \\
\end{array}$ & $\begin{array}{l}86,90 \\
90,86 \\
\end{array}$ & $\begin{array}{l}0,0 \\
0,0 \\
\end{array}$ & $\begin{array}{l}2,1 \\
0,0 \\
\end{array}$ & $\begin{array}{l}100,99 \\
98,96 \\
\end{array}$ & $\begin{array}{l}0,0 \\
0,0 \\
\end{array}$ & $\begin{array}{l}100,100 \\
100,100 \\
\end{array}$ & $\begin{array}{l}99,100 \\
100,100 \\
\end{array}$ \\
\hline
\end{tabular}




\begin{tabular}{|c|c|c|c|c|c|c|c|c|c|c|c|c|c|c|c|c|c|c|}
\hline & ${ }^{*}$ Belgium & 40 & 0 & 0 & 100 & 0 & 77 & 0 & 64 & 0 & 0 & 100 & 0 & 97 & 100 & 100 & 0 & 7 \\
\hline & & 64 & 0 & 0 & 77 & 0 & 36 & 0 & 34 & 0 & 0 & 99 & 0 & 96 & 98 & 100 & 0 & 9 \\
\hline \multirow[t]{4}{*}{ Bicycle (urban) } & Australia & 40 & 14,27 & 0,0 & 4,3 & 50,32 & 0,0 & 0,0 & 64,65 & 0,0 & 2,1 & 86,89 & 0,0 & 9,11 & 92,97 & 3,1 & 95,93 & 67,66 \\
\hline & & 64 & 15,4 & 1,8 & 0,1 & 21,14 & 0,0 & 0,0 & 75,71 & 0,0 & 4,3 & 86,90 & 0,0 & 0,0 & 93,94 & 1,0 & 97,95 & 79,76 \\
\hline & "Belgium & 40 & 1 & 0 & 99 & 1 & 96 & 0 & 88 & 0 & 0 & 99 & 0 & 36 & 100 & 100 & 59 & 98 \\
\hline & & 64 & 0 & 1 & 95 & 0 & 85 & 0 & 85 & 0 & 0 & 96 & 0 & 0 & 100 & 100 & 30 & 94 \\
\hline Bicycle & "Belgium & 40 & 95 & 78 & 18 & 97 & 97 & 0 & 100 & 55 & 93 & 100 & 2 & 88 & 100 & 100 & 100 & 100 \\
\hline (rural/suburban) & & 64 & 88 & 92 & 0 & 95 & 98 & 0 & 100 & 60 & 97 & 100 & 5 & 4 & 100 & 100 & 100 & 100 \\
\hline \multirow[t]{4}{*}{ Bus (urban) } & Australia & 40 & 100,54 & 7,0 & 54,36 & 72,88 & 0,0 & 0,0 & 77,97 & 0,0 & 56,24 & 21,67 & 0,0 & 34,33 & 100,100 & 100,95 & 100,100 & 84,95 \\
\hline & & 64 & 99,68 & 30,0 & 33,12 & 56,71 & 0,0 & 0,0 & 95,98 & 0,0 & 60,26 & 7,66 & 1,0 & 0,0 & 100,100 & 100,91 & 99,100 & 92,98 \\
\hline & Belgium & 40 & 0,3 & 0,14 & 86,100 & 6,31 & 77,92 & 0,0 & 70,74 & 0,16 & 4,41 & 88,3 & 0,0 & 0,66 & 100,100 & 100,100 & 70,90 & 95,100 \\
\hline & & 64 & 0,13 & 0,29 & 84,99 & 0,4 & 75,92 & 0,0 & 78,75 & 0,21 & 10,49 & 87,12 & 1,0 & 0,0 & 100,100 & 100,100 & 62,89 & 98,100 \\
\hline \multirow[t]{4}{*}{ Car (urban/suburban) } & Australia & 40 & 72,87 & 72,75 & 98,98 & 100,99 & 74,42 & 0,0 & 99,99 & 39,33 & 85,63 & 99,100 & 28,48 & 98,99 & 100,100 & 100,100 & 100,100 & 100,100 \\
\hline & & 64 & 63,87 & 91,90 & 94,96 & 91,83 & 62,25 & 0,0 & 99,99 & 48,31 & 84,65 & 99,99 & 31,50 & 0,0 & 100,100 & 100,100 & 100,100 & 100,100 \\
\hline & Belgium & 40 & 3,20 & 1,0 & 100,99 & 18,13 & 92,89 & 0,0 & 86,65 & 3,0 & 11,0 & 96,100 & 0,0 & 38,38 & 100,100 & 100,100 & 71,100 & 98,91 \\
\hline & & 64 & 41,19 & 3,34 & 97,100 & 2,0 & 90,91 & 0,0 & 91,69 & 4,0 & 14,1 & 97,100 & 1,0 & 0,0 & 100,100 & 100,100 & 60,99 & 99,100 \\
\hline Car (rural/suburban) & "Belgium & 40 & 100 & 63 & 52 & 99 & 97 & 0 & 100 & 60 & 65 & 100 & 32 & 32 & 84 & 100 & 100 & 100 \\
\hline & & 64 & 100 & 73 & 34 & 99 & 98 & 0 & 99 & 60 & 66 & 99 & 35 & 0 & 65 & 100 & 100 & 100 \\
\hline \multirow{4}{*}{ Tram (urban) } & Australia & 40 & 17,25 & 0,0 & 44,38 & 59,52 & 0,0 & 0,0 & 45,14 & 0,0 & 19,22 & 49,29 & 0,0 & 2,10 & 81,85 & 0,0 & 98,99 & 81,75 \\
\hline & & 64 & 13,10 & 0,0 & 12,0 & 17,8 & 0,0 & 0,0 & 54,17 & 0,0 & 22,36 & 46,26 & 0,0 & 0,0 & 73,84 & 0,0 & 98,98 & 86,84 \\
\hline & "Belgium & 40 & 0 & 0 & 53 & 23 & 71 & 0 & 66 & 0 & 2 & 62 & 0 & 2 & 100 & 100 & 70 & 96 \\
\hline & & 64 & 0 & 0 & 40 & 0 & 68 & 0 & 73 & 0 & 2 & 69 & 0 & 0 & 100 & 100 & 96 & 97 \\
\hline \multirow[t]{4}{*}{ Train } & Australia & 40 & 99,100 & 12,5 & 46,27 & 78,80 & 0,0 & 0,0 & 0,19 & 14,7 & 32,26 & 1,10 & 18,3 & 0,18 & 88,98 & 78,8 & 99,100 & 70,89 \\
\hline & & 64 & 99,100 & 28,22 & 1,12 & 21,34 & 0,0 & 0,0 & 3,24 & 8,7 & 27,31 & 2,10 & 16,5 & 0,0 & 74,91 & 70,73 & 99,99 & 85,97 \\
\hline & Belgium & 40 & 78,81 & 47,73 & 71,60 & 53,59 & 70,2 & 0,0 & 94,66 & 42,51 & 58,71 & 57,3 & 22,9 & 94,43 & 100,100 & 100,100 & 96,97 & 100,84 \\
\hline & & 64 & 59,83 & 56,77 & 68,50 & 7,10 & 68,1 & 0,0 & 94,62 & 41,47 & 62,77 & 59,3 & 20,14 & 0,0 & 100,92 & 100,100 & 93,94 & 100,91 \\
\hline \multirow{6}{*}{$\begin{array}{l}\text { *Subway station/ride } \\
\text { (urban) } \\
\text { Residential outdoor } \\
\text { (rural/suburban) }\end{array}$} & Australia & 40 & 24 & 95 & 63 & 98 & 2 & 0 & 94 & 12 & 8 & 58 & 96 & 47 & 100 & 100 & 100 & 97 \\
\hline & & 64 & 5 & 84 & 85 & 59 & 0 & 0 & 94 & 8 & 7 & 58 & 95 & 0 & 98 & 100 & 100 & 97 \\
\hline & Australia & 40 & 28,4 & 11,6 & 99,100 & 100,100 & 11,4 & 0,0 & 100,100 & 11,1 & 56,23 & 100,99 & 0,0 & 97,81 & 100,100 & 100,100 & 100,100 & 100,100 \\
\hline & & 64 & 3,15 & 46,53 & 89,98 & 96,100 & 1,0 & 0,0 & 100,100 & 11,4 & 77,34 & 100,100 & 0,1 & 0,0 & 100,100 & 100,100 & 100,100 & 100,100 \\
\hline & Belgium & 40 & 100,100 & 100,58 & 99,100 & 31,16 & 96,99 & 0,0 & 98,100 & 43,50 & 98,98 & 100,99 & 25,16 & 42,74 & 100,100 & $\begin{array}{l}98,100 \\
\end{array}$ & $\begin{array}{l}99,100 \\
\end{array}$ & 99,100 \\
\hline & & 64 & 99,100 & 100,99 & 98,100 & 0,0 & 98,98 & 0,0 & 98,100 & 53,55 & 99,100 & 99,100 & 34,20 & 13,0 & 99,100 & 100,100 & 99,100 & 100,100 \\
\hline \multirow{4}{*}{$\begin{array}{l}\text { Residential indoor } \\
\text { (rural/suburban) }\end{array}$} & "Australia & 40 & 4 & 99 & 99 & 100 & 98 & 0 & 100 & 2 & 76 & 100 & 41 & 91 & 100 & 100 & 100 & 100 \\
\hline & & 64 & 15 & 100 & 100 & 99 & 72 & 0 & 100 & 7 & 100 & 100 & 63 & 0 & 100 & 100 & 100 & 100 \\
\hline & Belgium & 40 & 100,100 & 100,99 & 99,100 & 100,100 & 92,100 & 0,0 & 100,100 & 99,100 & 99,100 & 99,100 & 100,99 & 0,0 & 100,99 & 100,100 & 100,100 & 100,100 \\
\hline & & 64 & 100,100 & 100,99 & 99,100 & 89,59 & 91,99 & 4,0 & 100,100 & 99,100 & 100,99 & 99,100 & 99,100 & 0,0 & 99,100 & 100,100 & 100,100 & 100,100 \\
\hline \multirow[t]{4}{*}{${ }^{*}$ Airport indoor } & Australia & 40 & 100 & 65 & 85 & 95 & 7 & 0 & 53 & 5 & 62 & 16 & 0 & 0 & 100 & & 100 & 73 \\
\hline & & 64 & 100 & 67 & 67 & 78 & 4 & 0 & 54 & 2 & 61 & 16 & 0 & 0 & 95 & 41 & 100 & 89 \\
\hline & Belgium & 40 & 100 & 94 & 100 & 100 & 22 & 0 & 1 & 0 & 23 & 9 & 0 & 0 & 100 & 100 & 100 & 83 \\
\hline & & 64 & 100 & 92 & 100 & 100 & 18 & 0 & 6 & 0 & 48 & 17 & 0 & 0 & 100 & 100 & 100 & 95 \\
\hline \multirow{2}{*}{$\begin{array}{l}{ }^{*} \text { Mountain/forest } \\
\text { (rural) }\end{array}$} & Australia & 40 & 100 & 91 & 100 & 100 & 100 & 0 & 100 & 100 & 100 & 100 & 100 & 100 & 99 & 100 & 100 & 100 \\
\hline & & 64 & 100 & 100 & 100 & 99 & 100 & 0 & 100 & 100 & 100 & 100 & 100 & 100 & 100 & 100 & 100 & 100 \\
\hline
\end{tabular}




\section{Appendix B}

\section{Calibration procedure}

The calibration procedure consisted of two steps. In step one, the $E_{\text {inc }}$ emitted by the transmitting antenna ( $\left.\mathrm{T}_{\mathrm{X}}\right)$ was measured without the subject present. For this, measurements of $E_{\text {inc }}$ were carried out along a vertical axis on the future assigned position of the subject in the measurement set-up using a Narda NBM-550 broadband field meter (Narda, Hauppauge, NY, USA). The (quadratic) $E_{\text {inc }}$ values were then averaged over the height of the subject. This was repeated for two orthogonal polarizations of the $T_{\mathrm{X}}$ : parallel to the four walls of the chamber ( $\mathrm{V}$ polarization) and parallel to the floor of the chamber (H polarization). This was also repeated for every centre frequency of the 15 frequency bands (DVB-T and higher) that could be calibrated in the available chamber.

In step two, the subject equipped with the ExpoM-RF 64 took place on the rotational platform in the far field of the $\mathrm{T}_{\mathrm{X}}$ (see Fig. 2a). The subject was rotated over $360^{\circ}$ in azimuthal direction, while being exposed to the previously measured constant incident $E_{i n c}$, which was V-polarized during a first rotation and then H-polarized. This rotation is executed in order to emulate an unknown orientation of the subject in an exposure situation (Thielens et al., 2013). During these rotations the $T_{X}$ subsequently emitted each one of the central frequencies of the studied frequency bands, while the ExpoM-RF recorded the electric fields on the body $\left(E_{b o d y}\right)$.

The recorded $E_{\text {body }}$ values were not the same as the incident fields (Thielens et al., 2015a), but rather provided a distribution depending on the angle of incidence and the incident polarization (Thielens et al., 2013, 2015b, Vanveerdeghem et al., 2015). Therefore, the ratio of $E_{b o d y}$ and $E_{\text {inc }}$ was studied using the ExpoM-RF's response, $R=E_{\text {body }} / E_{\text {inc }}$, where $R>1$ indicated an overestimation of $E_{\text {inc }}$, and $R<1$ indicated an underestimation. $R$ was determined in the post-processing of the calibration measurements, where a uniformly random angle of incidence and polarization was considered to determine the distribution of $R$. This distribution is characterized by its median value $\left(p_{50}(R)\right)$ and its $50 \%$ prediction interval $\left(P I_{50}\right)$ :

$$
P I_{50}=\frac{p_{75}(R)}{p_{25}(R)}
$$

with $p_{75}(R)$ and $p_{25}(R)$ indicating the $75^{\text {th }}$ and $25^{\text {th }}$ percentiles of $R$, respectively. A small value of $\mathrm{PI}_{50}$ is desirable.

During the exposure assessment in the microenvironments, the ExpoM-RFs measured $E_{b o d y}$ values, which were used to estimate incident field strengths $\left(\widehat{E}_{\text {inc }}\right)$, using this response. In this study, we estimated $\hat{E}_{\text {inc }}$, using the median $\left(p_{50}(R)\right)$ :

$$
\widehat{E}_{\text {inc }}=\frac{E_{\text {meas }}}{p_{50}(R)}
$$

with $E_{\text {meas }}$, the measured electric field strength. The uncertainty on this estimation is quantified using the $P I_{50}$.

Thielens et al. (2015a, b) demonstrated that the $P I_{50}$ value can be reduced, when multiple exposimeters are used simultaneously. Therefore, the subject was equipped with one ExpoM-RF on each hip, during the exposure assessment. Since only one ExpoM-RF was calibrated on the body, the same response was assumed for the second one, with this difference that the angular dependence was reflected with respect to the sagittal plane of the subject. The measured electric field values were averaged using a geometric average and were corrected for the influence of the body using Eq. 2.

During the calibration measurements, $E_{\text {body }}$ values were registered in each frequency band, regardless of the emitted frequency. These measurements were used to determine the cross-talk of the ExpoM-RF. Cross-talk is defined as the ratio of the electric field strength value registered in a certain frequency band and the incident field strength in the band in which the electric field was actually emitted. Ideally, 
the cross-talk matrix equals the identity matrix: one on the main diagonal and zero off-diagonal. However, Thielens et al. (2015a) demonstrated that exposimeters can exhibit large off-diagonal crosstalk values. Cross-talk is problematic for personal exposure measurements, since it causes the registration of non-existent exposure values.

Following the on-body calibration, the ExpoM-RF 64 was also calibrated in free-space in the same anechoic chamber. Firstly, the ExpoM-RF 64 was placed vertically at a height of $1.5 \mathrm{~m}$ above the rotating platform supported by a polystyrene arm, while the $T_{X}$ was oriented vertically as well. $T$ he $T_{X}$ subsequently emitted a continuous wave at the lowest frequency, the central frequency, and the highest frequency in each of the 15 studied frequency bands, with a constant input power in the antenna. Simultaneously, the ExpoM-RF recorded electric field values $\left(E_{\text {expom }}\right)$. These were then divided by the $E_{\text {inc }}$ values measured in the previous on-body calibration in order to determine the free-space cross-talk and responses. 
Table 3. Median cross-talk values of ExpoM-RF 64 measured on the body of the subject.

\begin{tabular}{|c|c|c|c|c|c|c|c|c|c|c|c|c|c|c|c|}
\hline $\begin{array}{l}\text { Regceived } \\
\text { Emitted }\end{array}$ & 定 & 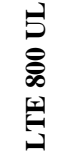 & 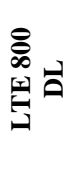 & $\sum_{\substack{0 \\
\vdots}}^{\infty}$ & 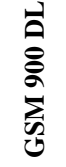 & 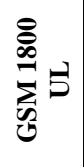 & $\sum_{\substack{0 \\
:}}^{\stackrel{8}{0}}$ & $\begin{array}{l}\text { ț } \\
\text { 돔 }\end{array}$ & $\begin{array}{l}S \\
\infty \\
\vdots \\
S\end{array}$ & 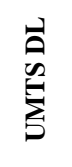 & 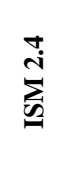 & 1 & 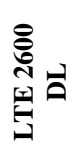 & $\sum_{\substack{n \\
n}}^{n}$ & $\sum_{\substack{n\\
}}^{\infty}$ \\
\hline DVB-T & 0.48 & 0.05 & 0.04 & 0.05 & 0.08 & 0.02 & 0.02 & 0.02 & 0.01 & 0.02 & 0.07 & 0.02 & 0.02 & 0.02 & 0.03 \\
\hline $\begin{array}{c}\text { LTE } 800 \\
\text { UL }\end{array}$ & 0.03 & 0.58 & 0.01 & 0.01 & 0.02 & 0.01 & 0.00 & 0.00 & 0.00 & 0.00 & 0.01 & 0.00 & 0.00 & 0.00 & 0.01 \\
\hline $\begin{array}{c}\text { LTE } 800 \\
\text { DL }\end{array}$ & 0.00 & 0.02 & 0.47 & 0.01 & 0.01 & 0.00 & 0.00 & 0.00 & 0.00 & 0.00 & 0.01 & 0.00 & 0.00 & 0.00 & 0.02 \\
\hline $\begin{array}{c}\text { GSM900 } \\
\text { UL }\end{array}$ & 0.00 & 0.01 & 0.01 & 0.53 & 0.01 & 0.00 & 0.00 & 0.00 & 0.00 & 0.00 & 0.01 & 0.00 & 0.00 & 0.00 & 0.01 \\
\hline $\begin{array}{c}\text { GSM900 } \\
\text { DL }\end{array}$ & 0.00 & 0.01 & 0.01 & 0.01 & 0.44 & 0.00 & 0.00 & 0.00 & 0.00 & 0.00 & 0.01 & 0.00 & 0.00 & 0.00 & 0.01 \\
\hline $\begin{array}{c}\text { GSM1800 } \\
\text { UL }\end{array}$ & 0.00 & 0.01 & 0.01 & 0.01 & 0.02 & 0.55 & 0.00 & 0.00 & 0.00 & 0.00 & 0.01 & 0.00 & 0.00 & 0.00 & 0.07 \\
\hline $\begin{array}{c}\text { GSM } 1800 \\
\text { DL }\end{array}$ & 0.00 & 0.01 & 0.01 & 0.01 & 0.02 & 0.01 & 0.43 & 0.01 & 0.00 & 0.00 & 0.02 & 0.00 & 0.00 & 0.00 & 0.07 \\
\hline DECT & 0.00 & 0.01 & 0.01 & 0.01 & 0.02 & 0.01 & 0.25 & 0.49 & 0.00 & 0.00 & 0.02 & 0.01 & 0.00 & 0.00 & 0.07 \\
\hline UMTS UL & 0.01 & 0.01 & 0.01 & 0.01 & 0.02 & 0.01 & 0.01 & 0.00 & 0.73 & 0.01 & 0.02 & 0.01 & 0.00 & 0.01 & 0.13 \\
\hline UMTS DL & 0.01 & 0.01 & 0.01 & 0.01 & 0.02 & 0.01 & 0.01 & 0.00 & 0.00 & 0.72 & 0.02 & 0.01 & 0.00 & 0.01 & 0.10 \\
\hline ISM 2.4 & 0.01 & 0.02 & 0.01 & 0.01 & 0.03 & 0.01 & 0.01 & 0.00 & 0.00 & 0.01 & 0.99 & 0.01 & 0.01 & 0.01 & 0.02 \\
\hline $\begin{array}{c}\text { LTE } 2600 \\
\text { UL }\end{array}$ & 0.01 & 0.01 & 0.01 & 0.01 & 0.02 & 0.01 & 0.01 & 0.00 & 0.01 & 0.01 & 0.02 & 1.29 & 0.01 & 0.01 & 0.05 \\
\hline $\begin{array}{c}\text { LTE } 2600 \\
\text { DL }\end{array}$ & 0.01 & 0.01 & 0.01 & 0.01 & 0.02 & 0.01 & 0.01 & 0.01 & 0.01 & 0.01 & 0.02 & 0.01 & 1.07 & 0.01 & 0.09 \\
\hline $\begin{array}{c}\text { WiMAX } \\
\mathbf{3 . 5}\end{array}$ & 0.01 & 0.01 & 0.01 & 0.01 & 0.02 & 0.01 & 0.01 & 0.00 & 0.00 & 0.00 & 0.01 & 0.01 & 0.01 & 0.89 & 0.35 \\
\hline ISM 5.8 & 0.01 & 0.02 & 0.02 & 0.02 & 0.04 & 0.01 & 0.01 & 0.01 & 0.01 & 0.01 & 0.03 & 0.01 & 0.01 & 0.01 & 3.13 \\
\hline
\end{tabular}

Table 4. Median cross-talk values of ExpoM-RF 64 measured off-body for a vertically polarized $\mathrm{T}_{\mathrm{X}}$ antenna and a vertically placed ExpoM-RF 64 for the lower edge, the middle, and the upper edge of the listed frequency bands, respectively. 


\begin{tabular}{|c|c|c|c|c|c|c|c|c|c|c|c|c|c|c|c|}
\hline Received & 定 & 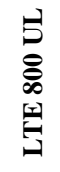 & 싱 & 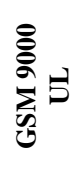 & 占 & $\sum_{\substack{0 \\
:}}^{\stackrel{8}{0}}$ & $\sum_{\substack{0 \\
0}}^{\stackrel{\infty}{0}}$ & 氜 & $\begin{array}{l}S \\
\infty \\
S \\
S\end{array}$ & $\stackrel{\overrightarrow{0}}{\omega}$ & 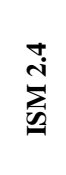 & لـ & هُ & $\sum_{\substack{n \\
x}}^{n}$ & $\sum_{\substack{n\\
}}^{\infty}$ \\
\hline DVB-T & $\begin{array}{c}2.12 \\
-2.6- \\
1.38\end{array}$ & $\begin{array}{c}0.06 \\
- \\
0.05 \\
- \\
6.05 \\
\end{array}$ & $\begin{array}{l}0.05- \\
0.04- \\
0.05\end{array}$ & $\begin{array}{c}0.04 \\
- \\
0.04 \\
- \\
0.04\end{array}$ & $\begin{array}{c}0.09 \\
- \\
0.09 \\
- \\
0.09\end{array}$ & $\begin{array}{c}0.03 \\
- \\
0.03 \\
- \\
0.03\end{array}$ & $\begin{array}{c}0.02 \\
- \\
0.02 \\
- \\
0.02\end{array}$ & $\begin{array}{c}0.02 \\
- \\
0.02 \\
- \\
0.02\end{array}$ & $\begin{array}{c}0.02 \\
- \\
0.02 \\
- \\
0.02\end{array}$ & $\begin{array}{c}0.02 \\
- \\
0.02 \\
- \\
0.02\end{array}$ & $\begin{array}{c}0.08 \\
- \\
0.07 \\
- \\
0.07\end{array}$ & $\begin{array}{c}0.02 \\
- \\
0.02 \\
- \\
0.02\end{array}$ & $\begin{array}{c}0.02 \\
- \\
0.02 \\
- \\
0.02\end{array}$ & $\begin{array}{c}0.02 \\
- \\
0.02 \\
- \\
0.02\end{array}$ & $\begin{array}{c}0.04 \\
- \\
0.05 \\
- \\
0.05\end{array}$ \\
\hline $\begin{array}{c}\text { LTE } 800 \\
\text { UL }\end{array}$ & $\begin{array}{c}0.35 \\
- \\
0.15 \\
- \\
0.01\end{array}$ & $\begin{array}{c}1.62 \\
- \\
1.81 \\
-1.6\end{array}$ & $\begin{array}{c}0.01- \\
0.01- \\
0.02\end{array}$ & $\begin{array}{c}0.01 \\
- \\
0.01 \\
- \\
0.01 \\
\end{array}$ & $\begin{array}{c}0.02 \\
- \\
0.02 \\
- \\
0.02 \\
\end{array}$ & $\begin{array}{c}0.01 \\
- \\
0.01 \\
- \\
0.01 \\
\end{array}$ & $\begin{array}{c}0.01 \\
- \\
0.01 \\
- \\
0.01 \\
\end{array}$ & $\begin{array}{c}0-0- \\
0\end{array}$ & $\begin{array}{c}0-0- \\
0\end{array}$ & $\begin{array}{c}0-0- \\
0\end{array}$ & $\begin{array}{c}0.02 \\
- \\
0.02 \\
- \\
0.02 \\
\end{array}$ & $\begin{array}{c}0.01 \\
- \\
0.01 \\
- \\
0.01 \\
\end{array}$ & $\begin{array}{c}0-0- \\
0\end{array}$ & $\begin{array}{c}0.01 \\
- \\
0.01 \\
- \\
0.01 \\
\end{array}$ & $\begin{array}{c}0.02 \\
- \\
0.01 \\
- \\
0.01 \\
\end{array}$ \\
\hline $\begin{array}{c}\text { LTE } 800 \\
\text { DL }\end{array}$ & $\begin{array}{c}0.01 \\
- \\
0.01 \\
- \\
0.01\end{array}$ & $\begin{array}{c}0.03 \\
- \\
0.04 \\
- \\
0.02\end{array}$ & $\begin{array}{c}1.2- \\
1.43- \\
1.14\end{array}$ & $\begin{array}{c}0.01 \\
- \\
0.01 \\
- \\
0.01\end{array}$ & $\begin{array}{c}0.02 \\
- \\
0.02 \\
- \\
0.02\end{array}$ & $\begin{array}{c}0.01 \\
- \\
0.01 \\
- \\
0.01\end{array}$ & $\begin{array}{c}0.01 \\
- \\
0.01 \\
- \\
0.01\end{array}$ & $\begin{array}{c}0-0- \\
0\end{array}$ & $\begin{array}{c}0-0- \\
0\end{array}$ & $\begin{array}{c}0-0- \\
0\end{array}$ & $\begin{array}{c}0.02 \\
- \\
0.01 \\
- \\
0.01\end{array}$ & $\begin{array}{c}0-0- \\
0\end{array}$ & $\begin{array}{c}0-0- \\
0\end{array}$ & $\begin{array}{c}0-0- \\
0\end{array}$ & $\begin{array}{c}0.01 \\
- \\
0.01 \\
- \\
0.02\end{array}$ \\
\hline $\begin{array}{c}\text { GSM900 } \\
\text { UL }\end{array}$ & $\begin{array}{c}0-0- \\
0\end{array}$ & $\begin{array}{c}0.02 \\
- \\
0.01 \\
- \\
0.01 \\
\end{array}$ & $\begin{array}{c}0.01- \\
0.01- \\
0.01\end{array}$ & $\begin{array}{c}1.03 \\
- \\
1.29 \\
- \\
0.59 \\
\end{array}$ & $\begin{array}{c}0.02 \\
- \\
0.02 \\
- \\
0.02 \\
\end{array}$ & $\begin{array}{c}0.01 \\
-0- \\
0.01\end{array}$ & $\begin{array}{c}0-0- \\
0\end{array}$ & $\begin{array}{c}0-0- \\
0\end{array}$ & $\begin{array}{c}0-0- \\
0\end{array}$ & $\begin{array}{c}0-0- \\
0\end{array}$ & $\begin{array}{c}0.01 \\
- \\
0.01 \\
- \\
0.02 \\
\end{array}$ & $\begin{array}{c}0-0- \\
0\end{array}$ & $\begin{array}{c}0-0- \\
0\end{array}$ & $\begin{array}{c}0-0- \\
0\end{array}$ & $\begin{array}{c}0.01 \\
- \\
0.01 \\
- \\
0.01 \\
\end{array}$ \\
\hline $\begin{array}{c}\text { GSM900 } \\
\text { DL }\end{array}$ & $\begin{array}{c}0-0- \\
0\end{array}$ & $\begin{array}{c}0.01 \\
- \\
0.01 \\
- \\
0.01\end{array}$ & $\begin{array}{c}0.01- \\
0.01- \\
0.01\end{array}$ & $\begin{array}{c}0.01 \\
- \\
0.01 \\
- \\
0.01\end{array}$ & $\begin{array}{c}1.2- \\
0.67 \\
- \\
0.32\end{array}$ & $\begin{array}{c}0.01 \\
- \\
0.01 \\
- \\
0.01\end{array}$ & $\begin{array}{c}0-0- \\
0\end{array}$ & $\begin{array}{c}0-0- \\
0\end{array}$ & $\begin{array}{c}0-0- \\
0\end{array}$ & $\begin{array}{c}0-0- \\
0\end{array}$ & $\begin{array}{c}0.02 \\
- \\
0.02 \\
- \\
0.02\end{array}$ & $\begin{array}{c}0-0- \\
0\end{array}$ & $\begin{array}{c}0-0- \\
0\end{array}$ & $\begin{array}{c}0-0- \\
0\end{array}$ & $\begin{array}{c}0.01 \\
- \\
0.01 \\
- \\
0.02\end{array}$ \\
\hline $\begin{array}{c}\text { GSM180 } \\
\text { 0 UL }\end{array}$ & $\begin{array}{c}0-0- \\
0\end{array}$ & $\begin{array}{c}0.01 \\
- \\
0.01 \\
- \\
0.01 \\
\end{array}$ & $\begin{array}{c}0.01- \\
0.01- \\
0.01\end{array}$ & $\begin{array}{c}0.01 \\
- \\
0.01 \\
- \\
0.01\end{array}$ & $\begin{array}{c}0.02 \\
- \\
0.02 \\
- \\
0.02\end{array}$ & $\begin{array}{c}0.99 \\
- \\
1.25 \\
- \\
1.01 \\
\end{array}$ & $\begin{array}{l}0-0- \\
0.05\end{array}$ & $\begin{array}{c}0-0- \\
0\end{array}$ & $\begin{array}{c}0-0- \\
0\end{array}$ & $\begin{array}{c}0-0- \\
0\end{array}$ & $\begin{array}{c}0.01 \\
- \\
0.01 \\
- \\
0.01 \\
\end{array}$ & $\begin{array}{c}0-0- \\
0\end{array}$ & $\begin{array}{c}0-0- \\
0\end{array}$ & $\begin{array}{c}0-0- \\
0\end{array}$ & $\begin{array}{c}0.12 \\
- \\
0.17 \\
- \\
0.18 \\
\end{array}$ \\
\hline $\begin{array}{c}\text { GSM } \\
1800 \mathrm{DL}\end{array}$ & $\begin{array}{c}0.01 \\
- \\
0.01 \\
- \\
0.01 \\
\end{array}$ & $\begin{array}{c}0.01 \\
- \\
0.01 \\
- \\
0.01 \\
\end{array}$ & $\begin{array}{c}0.01- \\
0.01- \\
0.01\end{array}$ & $\begin{array}{c}0.01 \\
- \\
0.01 \\
- \\
0.01\end{array}$ & $\begin{array}{c}0.03 \\
- \\
0.02 \\
- \\
0.02\end{array}$ & $\begin{array}{c}0.01 \\
- \\
0.01 \\
- \\
0.01 \\
\end{array}$ & $\begin{array}{c}0.88 \\
- \\
0.97 \\
-0.8\end{array}$ & $\begin{array}{c}0- \\
0.02 \\
- \\
1.04\end{array}$ & $\begin{array}{c}0-0- \\
0\end{array}$ & $\begin{array}{l}0-0- \\
0.01\end{array}$ & $\begin{array}{c}0.03 \\
- \\
0.05 \\
- \\
0.04\end{array}$ & $\begin{array}{c}0- \\
0.01 \\
- \\
0.01\end{array}$ & $\begin{array}{c}0-0- \\
0\end{array}$ & $\begin{array}{c}0-0- \\
0\end{array}$ & $\begin{array}{c}0.19 \\
- \\
0.17 \\
- \\
0.07\end{array}$ \\
\hline DECT & $\begin{array}{c}0.01 \\
- \\
0.01 \\
- \\
0.01\end{array}$ & $\begin{array}{c}0.01 \\
- \\
0.01 \\
- \\
0.01\end{array}$ & $\begin{array}{c}0.01- \\
0.01- \\
0.01\end{array}$ & $\begin{array}{c}0.01 \\
- \\
0.01 \\
- \\
0.01\end{array}$ & $\begin{array}{c}0.02 \\
- \\
0.02 \\
- \\
0.02\end{array}$ & $\begin{array}{c}0.01 \\
- \\
0.01 \\
- \\
0.01\end{array}$ & $\begin{array}{c}0.85 \\
- \\
0.53 \\
- \\
0.06\end{array}$ & $\begin{array}{c}1.1- \\
1.06 \\
-1\end{array}$ & $\begin{array}{c}0- \\
0.01 \\
- \\
0.08\end{array}$ & $\begin{array}{c}0.01 \\
- \\
0.01 \\
- \\
0.01\end{array}$ & $\begin{array}{c}0.04 \\
- \\
0.03 \\
- \\
0.02\end{array}$ & $\begin{array}{c}0.01 \\
- \\
0.01 \\
- \\
0.01\end{array}$ & $\begin{array}{c}0-0- \\
0\end{array}$ & $\begin{array}{c}0-0- \\
0\end{array}$ & $\begin{array}{c}0.07 \\
- \\
0.15 \\
- \\
0.11\end{array}$ \\
\hline $\begin{array}{c}\text { UMTS } \\
\text { UL }\end{array}$ & $\begin{array}{c}0.01 \\
- \\
0.01 \\
- \\
0.01\end{array}$ & $\begin{array}{c}0.01 \\
- \\
0.01 \\
- \\
0.01\end{array}$ & $\begin{array}{c}0.01- \\
0.01- \\
0.01\end{array}$ & $\begin{array}{c}0.01 \\
- \\
0.01 \\
- \\
0.01\end{array}$ & $\begin{array}{c}0.03 \\
- \\
0.02 \\
- \\
0.02\end{array}$ & $\begin{array}{c}0.01 \\
- \\
0.01 \\
- \\
0.01\end{array}$ & $\begin{array}{c}0.01 \\
- \\
0.01 \\
- \\
0.01\end{array}$ & $\begin{array}{l}0.01 \\
-0-0\end{array}$ & $\begin{array}{c}1.2- \\
0.98 \\
- \\
0.71\end{array}$ & $\begin{array}{c}0.01 \\
- \\
0.01 \\
- \\
0.01\end{array}$ & $\begin{array}{c}0.02 \\
- \\
0.02 \\
- \\
0.02\end{array}$ & $\begin{array}{c}0.01 \\
- \\
0.01 \\
- \\
0.01\end{array}$ & $\begin{array}{c}0-0- \\
0\end{array}$ & $\begin{array}{c}0.01 \\
- \\
0.01 \\
- \\
0.01\end{array}$ & $\begin{array}{l}0.1- \\
0.2- \\
0.22\end{array}$ \\
\hline $\begin{array}{c}\text { UMTS } \\
\text { DL }\end{array}$ & $\begin{array}{c}0.01 \\
- \\
0.01 \\
- \\
0.01\end{array}$ & $\begin{array}{c}0.01 \\
- \\
0.01 \\
- \\
0.01\end{array}$ & $\begin{array}{c}0.01- \\
0.01- \\
0.01\end{array}$ & $\begin{array}{c}0.01 \\
- \\
0.01 \\
- \\
0.01\end{array}$ & $\begin{array}{c}0.02 \\
- \\
0.02 \\
- \\
0.02\end{array}$ & $\begin{array}{c}0.01 \\
- \\
0.01 \\
- \\
0.01\end{array}$ & $\begin{array}{c}0.01 \\
- \\
0.01 \\
- \\
0.01\end{array}$ & $\begin{array}{c}0-0- \\
0\end{array}$ & $\begin{array}{c}0-0- \\
0\end{array}$ & $\begin{array}{c}1.34 \\
-1.2- \\
0.89\end{array}$ & $\begin{array}{c}0.03 \\
- \\
0.03 \\
- \\
0.03\end{array}$ & $\begin{array}{c}0.01 \\
- \\
0.01 \\
- \\
0.01\end{array}$ & $\begin{array}{c}0-0- \\
0\end{array}$ & $\begin{array}{c}0.01 \\
- \\
0.01 \\
- \\
0.01\end{array}$ & $\begin{array}{c}0.18 \\
- \\
0.17 \\
- \\
0.13\end{array}$ \\
\hline ISM 2.4 & $\begin{array}{c}0.01 \\
- \\
0.01 \\
- \\
0.01\end{array}$ & $\begin{array}{c}0.02 \\
- \\
0.01 \\
- \\
0.01\end{array}$ & $\begin{array}{c}0.01- \\
0.01- \\
0.01\end{array}$ & $\begin{array}{c}0.01 \\
- \\
0.01 \\
- \\
0.01\end{array}$ & $\begin{array}{c}0.02 \\
- \\
0.02 \\
- \\
0.02\end{array}$ & $\begin{array}{c}0.01 \\
- \\
0.01 \\
- \\
0.01\end{array}$ & $\begin{array}{c}0.01 \\
- \\
0.01 \\
- \\
0.01\end{array}$ & $\begin{array}{c}0-0- \\
0\end{array}$ & $\begin{array}{c}0-0- \\
0\end{array}$ & $\begin{array}{c}0.01 \\
- \\
0.01 \\
- \\
0.01\end{array}$ & $\begin{array}{c}1.18 \\
- \\
1.26 \\
- \\
0.51\end{array}$ & $\begin{array}{c}0.01 \\
- \\
0.01 \\
- \\
0.36\end{array}$ & $\begin{array}{c}0.01 \\
- \\
0.01 \\
- \\
0.01\end{array}$ & $\begin{array}{c}0.01 \\
- \\
0.01 \\
- \\
0.01\end{array}$ & $\begin{array}{c}0.03 \\
- \\
0.03 \\
- \\
0.04\end{array}$ \\
\hline $\begin{array}{c}\text { LTE } \\
2600 \mathrm{UL}\end{array}$ & $\begin{array}{c}0.01 \\
- \\
0.01 \\
- \\
0.01\end{array}$ & $\begin{array}{c}0.02 \\
- \\
0.01 \\
- \\
0.01\end{array}$ & $\begin{array}{c}0.01- \\
0.01- \\
0.01\end{array}$ & $\begin{array}{c}0.01 \\
- \\
0.01 \\
- \\
0.01\end{array}$ & $\begin{array}{c}0.02 \\
- \\
0.02 \\
- \\
0.02\end{array}$ & $\begin{array}{c}0.01 \\
- \\
0.01 \\
- \\
0.01\end{array}$ & $\begin{array}{c}0.01 \\
- \\
0.01 \\
- \\
0.01\end{array}$ & $\begin{array}{c}0-0- \\
0\end{array}$ & $\begin{array}{c}0-0- \\
0\end{array}$ & $\begin{array}{c}0.01 \\
- \\
0.01 \\
- \\
0.01\end{array}$ & $\begin{array}{c}0.02 \\
- \\
0.02 \\
- \\
0.02\end{array}$ & $\begin{array}{c}0.61 \\
- \\
1.02 \\
- \\
1.26\end{array}$ & $\begin{array}{c}0.01 \\
- \\
0.01 \\
- \\
0.01\end{array}$ & $\begin{array}{c}0.01 \\
- \\
0.01 \\
- \\
0.01\end{array}$ & $\begin{array}{c}0.03 \\
- \\
0.04 \\
- \\
0.04\end{array}$ \\
\hline $\begin{array}{c}\text { LTE } \\
2600 \text { DL }\end{array}$ & $\begin{array}{c}0.01 \\
- \\
0.01 \\
- \\
0.01\end{array}$ & $\begin{array}{c}0.02 \\
- \\
0.01 \\
- \\
0.01\end{array}$ & $\begin{array}{c}0.01- \\
0.01- \\
0.01\end{array}$ & $\begin{array}{c}0.01 \\
- \\
0.01 \\
- \\
0.01\end{array}$ & $\begin{array}{c}0.03 \\
- \\
0.03 \\
- \\
0.03\end{array}$ & $\begin{array}{c}0.01 \\
- \\
0.01 \\
- \\
0.01\end{array}$ & $\begin{array}{c}0.01 \\
- \\
0.01 \\
- \\
0.01\end{array}$ & $\begin{array}{c}0.01 \\
- \\
0.01 \\
- \\
0.01\end{array}$ & $\begin{array}{c}0.01 \\
- \\
0.01 \\
- \\
0.01\end{array}$ & $\begin{array}{c}0.01 \\
- \\
0.01 \\
- \\
0.01\end{array}$ & $\begin{array}{c}0.02 \\
- \\
0.02 \\
- \\
0.02\end{array}$ & $\begin{array}{c}0.01 \\
- \\
0.01 \\
- \\
0.01\end{array}$ & $\begin{array}{c}0.77 \\
- \\
0.64 \\
- \\
0.79\end{array}$ & $\begin{array}{c}0.01 \\
- \\
0.01 \\
- \\
0.01\end{array}$ & $\begin{array}{c}0.06 \\
- \\
0.06 \\
- \\
0.07\end{array}$ \\
\hline $\begin{array}{c}\text { WiMAX } \\
\mathbf{3 . 5}\end{array}$ & $\begin{array}{c}0.01 \\
- \\
0.01\end{array}$ & $\begin{array}{c}0.01 \\
- \\
0.01\end{array}$ & $\begin{array}{l}0.01- \\
0.01- \\
0.01\end{array}$ & $\begin{array}{c}0.01 \\
- \\
0.01\end{array}$ & $\begin{array}{c}0.02 \\
- \\
0.02\end{array}$ & $\begin{array}{c}0.01 \\
- \\
0.01\end{array}$ & $\begin{array}{c}0.01 \\
- \\
0.01\end{array}$ & $\begin{array}{c}0-0- \\
0\end{array}$ & $\begin{array}{c}0-0- \\
0\end{array}$ & $\begin{array}{c}0-0- \\
0\end{array}$ & $\begin{array}{c}0.02 \\
- \\
0.01\end{array}$ & $\begin{array}{c}0.01 \\
- \\
0.01\end{array}$ & $\begin{array}{c}0.01 \\
- \\
0.01\end{array}$ & $\begin{array}{l}0.7- \\
0.38 \\
-0.2\end{array}$ & $\begin{array}{c}0.19 \\
- \\
0.14\end{array}$ \\
\hline
\end{tabular}




\begin{tabular}{|l|c|c|c|c|c|c|c|c|c|c|c|c|c|c|c|}
\hline & - & - & & - & - & - & - & & & & - & - & - & & - \\
& 0.01 & 0.01 & & 0.01 & 0.02 & 0.01 & 0.01 & & & & 0.01 & 0.01 & 0.01 & & 0.05 \\
\hline & 0.01 & 0.02 & & 0.02 & 0.04 & 0.01 & 0.01 & 0.01 & 0.01 & 0.01 & 0.03 & 0.01 & 0.01 & 0.01 & $1.3-$ \\
\multirow{5}{*}{ ISM 5.8 } & - & - & $0.02-$ & - & - & - & - & - & - & - & - & - & - & - & 2.17 \\
& 0.01 & 0.02 & $0.02-$ & 0.02 & 0.04 & 0.01 & 0.01 & 0.01 & 0.01 & 0.01 & 0.03 & 0.01 & 0.01 & 0.01 & - \\
& - & - & 0.02 & - & - & - & - & - & - & - & - & - & - & - & 1.23 \\
\hline
\end{tabular}

